Universidad de Lima

Facultad de Ciencias Empresariales y Económicas

Carrera de Contabilidad

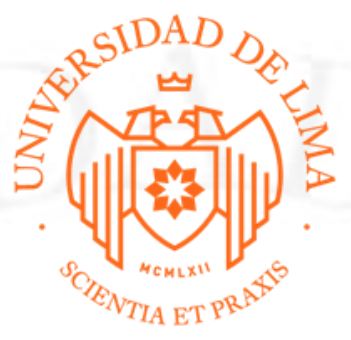

\title{
ANÁLISIS E INTERPRETACIÓN DE LOS ESTADOS FINANCIEROS Y SU IMPORTANCIA EN LA TOMA DE LAS DECISIONES CASO: LOS PORTALES S.A. PERIODOS 2015 - 2017
}

Trabajo de suficiencia profesional para optar el Título Profesional de Contador Público

\section{Cristian Alonso Luna Mori}

Código 20101676

\section{Asesor}

Julio César Del Castillo Vargas

$$
\text { Lima - Perú }
$$

Noviembre 2018 
ANÁLISIS E INTERPRETACIÓN DE LOS ESTADOS FINANCIEROS Y SU

IMPORTANCIA EN LA TOMA DE LAS

DECISIONES

CASO: LOS PORTALES S.A.

PERIODOS 2015 - 2017 


\section{DEDICATORIA}

Un especial agradecimiento a mi asesor Julio Del Castillo, por su excelente asesoría oportuna y los lineamientos ofrecidos. Sus amplios conocimientos, consejos y experiencia han sido fundamentales para la elaboración de la presente investigación, para optar por el título de Contador Público.

Asimismo, agradezco a la Universidad de Lima, por la invaluable labor de transmitir conocimientos enfocados al análisis en la gestión de negocios.

Finalmente, agradezco el apoyo, el cariño y el respaldo de mi familia durante todos estos meses de arduo sacrificio. Sin la ayuda de ellos no hubiera sido posible concluir la labor con satisfacción. 


\section{TABLA DE CONTENIDO}

INTRODUCCIÓN ........................................................................................... 1

CAPÍTULO I: ANTECEDENTES DE LA ENTIDAD ..................................3

1.1 Identificación y actividades económicas de la entidad..............................4

1.2 Presencia en el mercado...................................................................... 5

CAPÍTULO II: DESCRIPCIÓN Y OBJETIVOS DEL TRABAJO DE

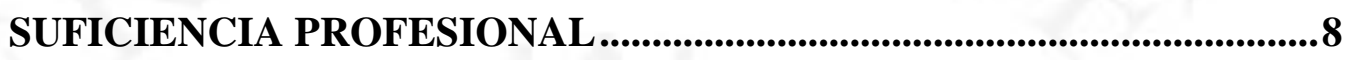

2.1 Descripción del caso de investigación ................................................... 8

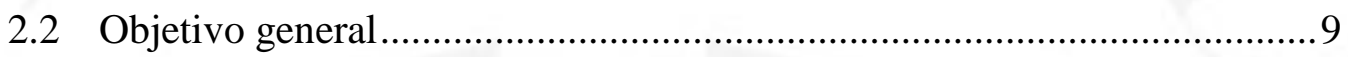

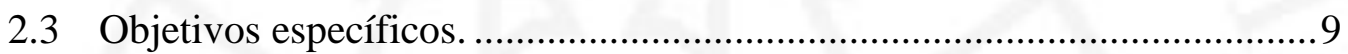

CAPÍTULO III: MARCO METODOLÓGICO ..............................................11

3.1 Metodología de recolección de la información......................................... 11

3.2 Metodología de análisis de la información ........................................... 12

CAPÍTULO IV: ANÁLISIS Y PRESENTACIÓN Y DISCUSIÓN DE

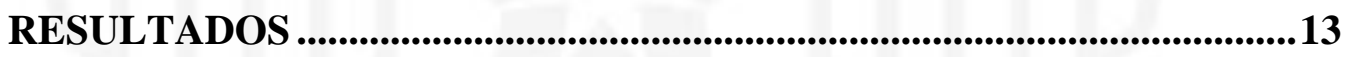

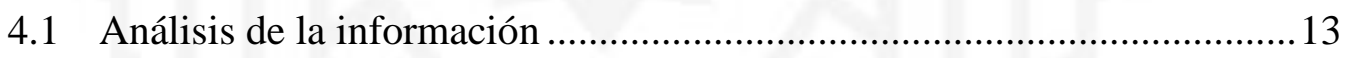

4.2 Presentación y discusión de resultados ................................................ 13

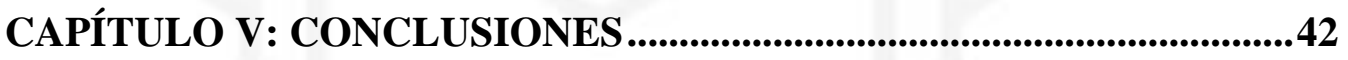

RECOMENDACIONES ...........................................................................44

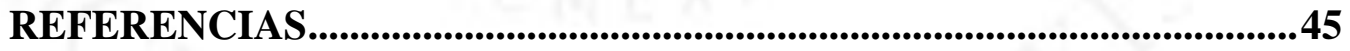

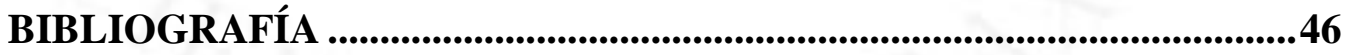

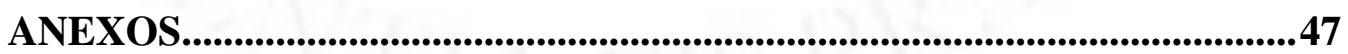




\section{ÍNDICE DE TABLAS}

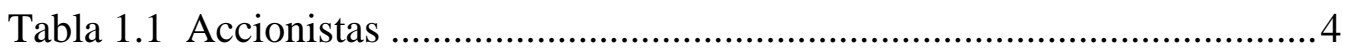

Tabla 1.2 Participación en las subsidiarias ...................................................6

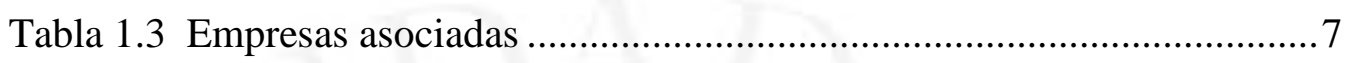

Tabla 4.1 Emisión de bonos corporativos y papeles comerciales del año 2017

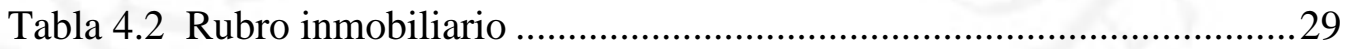

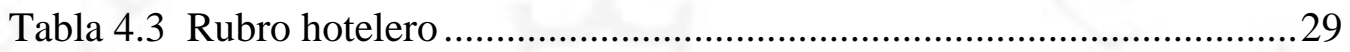

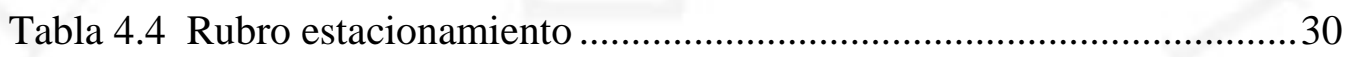

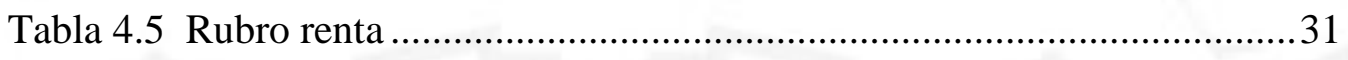

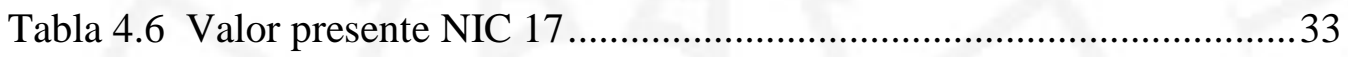

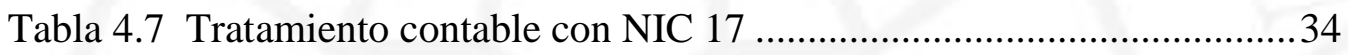

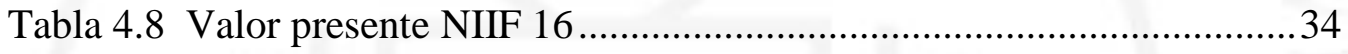

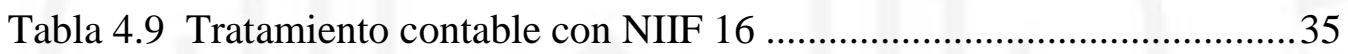

Tabla 4.10 Visitantes nacionales e internacionales (acumulado) ..................... 37

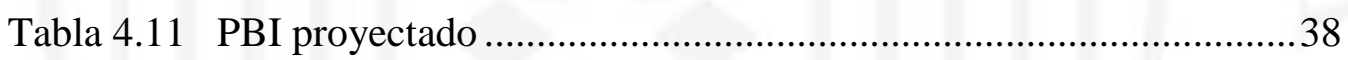

Tabla 4.12 Proyección para los estados financieros 2018 - 2020 


\section{ÍNDICE DE FIGURAS}

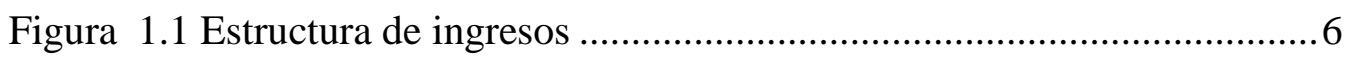

Figura 4.1 Composición de los inventarios de los años 2015-2017 ................ 14

Figura 4.2 Indicadores de liquidez de los años 2015-2017 ........................... 15

Figura 4.3 Evolución del capital de trabajo 2015-2017................................. 16

Figura 4.4 Composición de deuda de los años 2015-2017 ............................. 18

Figura 4.5 Ratios de solvencia de los años 2015-2017.................................. 19

Figura 4.6 Ratios de gestión de los años 2015-2017 ....................................21

Figura 4.7 Utilidad bruta de los años 2015-2017 ..........................................22

Figura 4.8 Márgenes bruto, operativo y neto de los años 2015-2017 .............23

Figura 4.9 Evolución de indicadores de rentabilidad de los años 2015-2017.24

Figura 4.10 Composición de inventarios que más impactaron en el 2017 ......25

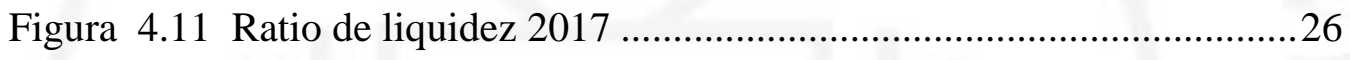

Figura 4.12 Capital de trabajo del año 2017 ................................................26

Figura 4.13 Ratios de solvencia del año 2017 ............................................27

Figura 4.14 Margen bruto de los años 2015-2017 .........................................28

Figura 4.15 Utilidad neta de los años 2015-2017 ......................................28

Figura 4.16 Participación del sector inmobiliario ..........................................29

Figura 4.17 Participación del sector hotelero ................................................. 30

Figura 4.18 Participación del sector estacionamiento .................................... 31

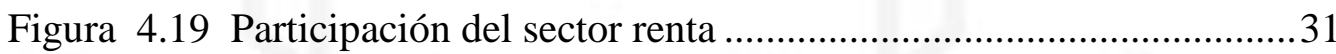

Figura 4.20 Encuestas del sector construcción del año 2018 .........................37 


\section{ÍNDICE DE ANEXOS}

ANEXO 1: Estado Separado de Resultados Los Portales S.A. .........................48

ANEXO 2: Estado Separado de Situación Financiera Los Portales S.A.......... 49

ANEXO 3: Estado de Resultados por segmento Los Portales S.A. - venta

inmobiliaria

ANEXO 4: Estado de Situación Financiera por segmento Los Portales S.A. -

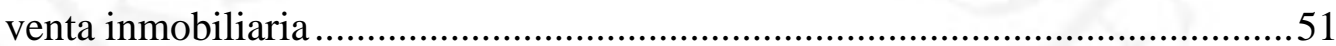

ANEXO 5: Estado de Resultado proyectado 2018-2020 …..............................53

ANEXO 6: Estado de Situación Financiera proyectado 2018-2020 .................53 


\section{INTRODUCCIÓN}

En un entorno empresarial cada vez más incierto, debido a la alta competitividad, productividad laboral, factores tecnológicos y políticos, entre otros, por lo cual es imprescindible que exista un constante análisis e interpretación de los estados financieros de una empresa que permita a la gerencia tomar decisiones oportunas y eficientes, con el fin de minimizar los riesgos de la incertidumbre económica y financiera. Cada vez es más exigible que las empresas sean competitivas en los contextos empresariales y eficientes en la toma de decisiones dentro de su sector económico, así como también que los inversionistas tengan la capacidad de interpretar los análisis realizados a los estados financieros de la empresa y puedan tomar decisiones en base a estos resultados.

Dicho análisis financiero nos da a conocer, cómo se encuentra sistemáticamente el negocio, cuál es su situación actual, saber si los resultados son los esperados y su posible diagnóstico en caso se esté manejando mal. Dicha información no solamente será importante para la empresa, sino también para los accionistas, ya que, junto con el directorio, tomarán decisiones económicas - financieras, operativas y tributarias que permitan a la empresa continuar con la senda del crecimiento o en el peor de los casos, elaborar estrategias para reflotar el negocio.

Por ejemplo, un Banco que realiza préstamos se enfoca en el flujo de caja proyectado, un inversionista en la rentabilidad que tiene la compañía, un accionista en el pago de dividendos, entre otros.

De muchos conceptos sobre la información financiera, se rescata lo siguiente: " $L a$ interpretación financiera es de gran importancia para el desarrollo de las diferentes actividades que se llevan a cabo dentro de la empresa. Esta interpretación permite a los usuarios internos y externos conocer el desempeño de la compañía" (Córdova, 2014, p.14).

No olvidemos que cada empresa tiene su estrategia de crecimiento económico, dicha estrategia se puede basar en incrementar las ventas, disminuir costos, invertir en propiedad, planta y equipo, etc. Es por ello, que es necesario evaluar la información financiera que nos ayude o permita analizar e interpretar los resultados, como son los ratios financieros. 
Los ratios financieros nos facilitan analizar y entender de manera global la compañía, tal es así que dichos indicadores son importantes en la toma de decisiones para un inversionista, banquero, cliente, proveedor, entre otros. Los indicadores financieros se pueden dividir en cuatro grupos que son: índice de liquidez, solvencia, gestión y rentabilidad. Es importante recalcar que el resultado mostrado por los indicadores dependerá del rubro o sector al que pertenezca la empresa.

En el presente trabajo de investigación, se examina la situación económica y financiera de la empresa Los Portales S.A., para lo cual se partió de un riguroso análisis de los estados financieros de los últimos tres años, asimismo, para ver su desarrollo en un futuro cercano se realizó una proyección de los mismos al año 2020. Se seleccionó a la empresa Los Portales S.A., porque es una empresa líder en el sector inmobiliario, sector que participa como gran impulsor del PBI del país.

Las cifras que fueron materia de estudio nos permiten elaborar las propuestas de generación de valor para la empresa Los Portales S.A.; se analizaron las tres principales líneas de negocios, en los cuales la empresa tiene importante participación, a fin de que sean los impulsores de crecimiento del negocio, y de esta manera, se pueda cumplir con el objetivo establecido por la compañía para los siguientes años.

A pesar que las ventas de Los Portales S.A. han disminuido durante el 2017 (producto de la corrupción en el país y Fenómeno del Niño Costero), fue una de las pocas empresas que incrementaron sus utilidades en el segmento inmobiliario. En dicho año la empresa vio mermado sus ingresos, sin embargo, aplicó una serie de estrategias que permitieron mantener una buena estructura en sus costos y en sus gastos operativos, con lo cual logró mejorar su utilidad.

Para poder obtener una mayor información sobre la investigación del análisis e interpretación financiera de la empresa Los Portales, se realizará o desarrollará en cinco capítulos.

Por último, se dará conclusiones y recomendaciones para una mejor eficiencia y eficacia para la toma de decisiones. 


\section{CAPÍTULO I: ANTECEDENTES DE LA ENTIDAD}

\section{Antecedentes de la entidad}

Los Portales S.A. se creó sobre la base de Consorcio Inmobiliario Los Portales S.A. (“CILPSA”), empresa constituida en marzo de 1996, y que surgió como consecuencia de la alianza estratégica entre: LP Holding S.A., empresa vinculada a la actividad inmobiliaria desde 1930, e Ingenieros Civiles Asociados (ICA) de México, una de las más importantes constructoras de México.

En setiembre de 1999, la junta general de accionistas (JGA) de CILPSA acordó la fusión por absorción con su subsidiaria Los Portales Consorcio Hotelero S.A.

En febrero del 2000, se acordó cambiar la denominación social de Consorcio Inmobiliario Los Portales S.A. a Los Portales S.A. ("LPSA"), nombre con el cual opera actualmente.

A lo largo de su vida útil, LPSA ha atravesado por fusiones y por diferentes procesos de reorganización societaria:

- En diciembre del 2005, se aprobó la fusión por absorción de la empresa Constructora ICA Perú S.A.

- En agosto del 2009, se aprobó la fusión por absorción de tres subsidiarias (Los Portales Negocios Inmobiliarios S.A.C., Promotora Huampaní S.A.C. y Promotora Golf S.A.C.).

- En abril del 2010, se acordó la escisión de un bloque patrimonial constituido por las acciones de Inversiones Centenario S.A.A., el mismo que fue aportado a una sociedad pre- existente y se aprobó la fusión por absorción de la subsidiaria Constructora Los Portales S.A. y las empresas vinculadas Inversiones en Inmuebles S.A. ("INISA") e Inversiones de Estacionamientos S.A. ("IESA").

- En noviembre del 2011, se aprobó la fusión por absorción de la subsidiara Los Portales Estacionamientos S.A.C. 


\subsection{Identificación y actividades económicas de la entidad Presencia en el mercado.}

Entre sus actividades se encuentran el desarrollo de proyectos de habilitación urbana, venta de departamentos, administración de playas de estacionamiento, servicio de hoteles y operaciones de rentas inmobiliarias.

Los Portales S.A. es una empresa que en el transcurso del tiempo ha estado creciendo y se ha posicionado como líder en el mercado inmobiliario peruano. Actualmente, sus actividades de negocio ocupan más del 30\% de participación en el mercado nacional. Asimismo, se encuentra registrada en la Bolsa de Valores de Lima, en el cual se puede encontrar con la denominación "PORTAC 1"

\section{Capital social y composición accionaria}

“Al 31 de diciembre de 2017, el capital social suscrito y pagado de la sociedad es de S/ 171, 253,798, representada por 171, 253,798 acciones de un valor nominal de S/ 1 cada una, totalmente suscritas y pagadas" (Superintendencia de Mercado de Valores, 2018, p. 23).

Actualmente, existen 3 accionistas que ayudaron al fortalecimiento económico de la empresa Los Portales S.A., uno de ellos pertenece a una empresa con capital peruano que es el Grupo Raffo con el 50\% de las acciones de la empresa GR Holding S.A. y las otras 2 con capitales extranjeros, la primera es la empresa constructoras ICA S.A.B de C.V y la otra Ingenieros Civiles Asociados S.A. de C.V que pertenecen al Grupo ICA de México.

Tabla 1.1

Accionistas

\begin{tabular}{|c|c|}
\hline Accionistas & \% de acciones \\
\hline GR Holding S.A. & $50.00 \%$ \\
\hline Constructora ICA e Ingenieros Civiles Asociados S.A. & $49.99 \%$ \\
\hline Otros & $0.01 \%$ \\
\hline Total & $\mathbf{1 0 0 . 0 0 \%}$ \\
\hline
\end{tabular}

Fuente: SMV (2017)

Elaboración propia 


\subsection{Presencia en el mercado}

\section{Actividades económicas que maneja los portales:}

a) Unidad de vivienda (Inmobiliario)

En esta unidad de negocio está compuesto por tres actividades. La primera es el desarrollo de viviendas que se realiza la etapa pre operativa (planos), la segunda es la venta (edificios, casa de playa, entre otras) y por último es el financiamiento que se da por el desarrollo de servicios básicos o la venta de lotes de casa de playa o de campo.

Esta unidad incluye proyectos de habilitación urbana, los mismos que representan la mayor parte de los ingresos operativos y financieros de esta unidad, además de proyectos de edificación de viviendas de interés social a través de programas gubernamentales como Mivivienda, Techo Propio y proyectos multifamiliares de vivienda. Además, la compañía genera ingresos por el financiamiento directo que brinda a sus clientes (cobranzas a través de letras de cambio).

b) Unidad de estacionamiento

La empresa gestiona o administra estacionamientos propios y de terceros. Asimismo, se realiza servicios adicionales como lavado de autos, valet parking, publicidad, entre otros.

La empresa administra y opera 207 playas de estacionamientos a nivel nacional, en formatos que varían desde micro playas hasta concesiones con entidades gubernamentales. Esta unidad representa el $11.47 \%$ de los ingresos totales a la fecha de corte de análisis.

c) Unidad de hoteles

Esta unidad tiene como principal función en la administración de hoteles propios y de terceros de acuerdo al contrato establecido. Asimismo, dentro de ello se ofrece diversos servicios como el de alimentación, hospedaje, eventos, entro otros. Además, su unidad de negocio se encuentra en ciudades estratégicas como Piura, Lima, Cuzco, Lima y Tarma.

La compañía opera los hoteles Country Club Lima Hotel, Los Portales Hotel Tarma, Los Portales Hotel Piura, Los Portales Hotel Chiclayo y Los Portales Hotel Cuzco, y administra el hotel Las Arenas de Máncora, en Piura. Los ingresos generados por este negocio representan el 5.83\% de los ingresos totales del 2017. 
d) Unidad de rentas

Esta unidad de negocio genera ingresos por los arrendamientos de los locales comerciales y oficinas que son propiedad del edificio corporativo en que Los Portales S.A. basa sus operaciones o en el Boulevard del Hotel Country Club Lima” (Bedregal, G y Salazar. E., 2018, p. 3). Esta unidad genera el $0.27 \%$ de los ingresos de la compañía Los Portales S.A.

Podemos observar en el siguiente gráfico que el rubro que le genera mayores ingresos al grupo Los Portales S.A. es la venta de inmuebles con un promedio de $71.40 \%$, en pocas palabras del total proviene de ahí.

Figura 1.1

Estructura de ingresos

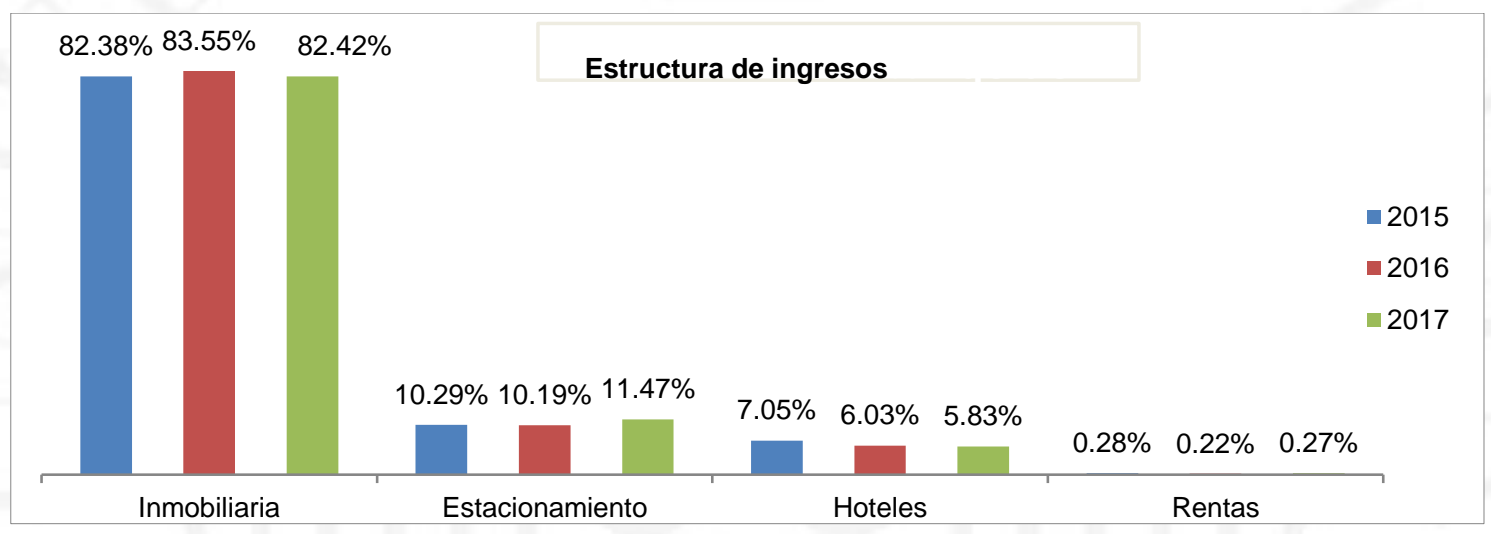

Fuente: Los Portales (2017).

Elaboración propia

\section{Relación de empresas subsidiarias y con influencia significativa}

Tabla 1.2

Participación en las subsidiarias

\begin{tabular}{|l|c|}
\hline \multicolumn{1}{|c|}{ Subsidiarias } & \% de acciones \\
\hline Los Portales Construye & $99.90 \%$ \\
\hline Consorcio Estacionamientos Gamarra S.A. & $99.90 \%$ \\
\hline Inversiones Nueva Etapa S.A.C & $99.80 \%$ \\
\hline Consorcio Los Portales S.A. & $100.00 \%$ \\
\hline LP USA S.A. & $99.80 \%$ \\
\hline Soluciones Urbanísticas S.A.C. & $99.90 \%$ \\
\hline
\end{tabular}

Fuente: SMV (2017)

Elaboración propia 


\section{Tabla 1.3}

\section{Empresas asociadas}

\begin{tabular}{|l|c|}
\hline \multicolumn{1}{|c|}{ Negocios Asociados } & \% de acciones \\
\hline Inversiones Real Once S.A. & $28.00 \%$ \\
\hline Concesión Estacionamientos Miraflores S.A. & $25.00 \%$ \\
\hline
\end{tabular}

Fuente: SMV (2017)

Elaboración propia 


\section{CAPÍTULO II: DESCRIPCIÓN Y OBJETIVOS DEL TRABAJO DE SUFICIENCIA PROFESIONAL}

\subsection{Descripción del caso de investigación}

Hoy en día en el Perú y en el mundo es importante desarrollar nuevas estrategias de crecimiento, en las cuales las compañías puedan optar por crecer de manera orgánica e inorgánica, por lo que es necesario que la gerencia actúe en base a la toma de decisiones de un buen manejo de los estados financieros, lo cual permite analizar e interpretar la información obtenida.

Analizar los estados financieros significa "realizar estudios de las relaciones entre los diversos elementos financieros de una entidad" (Análisis de empresas, 2005, p. 44). Mientras, Ferrer Quea, (2012) sostiene que la interpretación “consiste en la utilización de datos contables como punto de inicio para extraer nuestras propias conclusiones sobre los análisis realizados” (p.45).

La empresa Los Portales S.A. se ha caracterizado por tener políticas estratégicas marcadas en el crecimiento, expansión y constante innovación. Razón por la cual, se selecciona esta empresa materia de análisis. Para dicho análisis se tomaron los estados financieros de los años 2015, 2016 y 2017, los cuales sirvieron para analizar sus principales inversiones, sus principales fuentes de financiamiento, su liquidez, la gestión del negocio, situación de endeudamiento y logros de rentabilidad.

Se hace una descripción de los objetivos generales y específicos de la investigación, los cuales servirán de guía en el desarrollo del presente trabajo.

Asimismo, se realizó un análisis del sector y de las empresas competidoras, y el desempeño de Los Portales S.A. en dicho mercado.

En un capítulo posterior se analizará el impacto de las principales NIIF.

Por último, se dará conclusiones y recomendaciones para una mejor eficiencia y eficacia en la toma de decisiones. 


\subsection{Objetivo general}

El sector de construcción e inmobiliario, se caracteriza porque abarca un periodo de tiempo prolongado, es por ello que los criterios de reconocimiento de ingresos y la evaluación de los contratos, presentados por la NIIF 15, inciden en la presentación de los resultados económicos financieros de las empresas del sector. También es característica del sector los arrendamientos financieros, por lo que incidirá la futura aplicación de la NIIF 16, que busca asegurar que los arrendatarios y arrendadores proporcionen información relevante que represente fielmente las transacciones. Finalmente, la NIIF 9, será aplicada a las empresas de este sector, ya que las cuentas por cobrar de las inmobiliarias se realizan en periodos mayores a un año.

El presente estudio de investigación tiene como objetivo principal, analizar los criterios de reconocimiento, medición e impacto relacionado a los ingresos de efectivo de la empresa Los Portales S.A. y su relación a la implementación de la NIIF 9, NIIF 15 y NIIF 16 en comparación con la situación actual.

\subsection{Objetivos específicos.}

a) Analizar los Estados Financieros Separados del 2015 al 2017 auditados de la empresa Los Portales S.A. Información que nos ayudará conocer la situación y desempeño del negocio en lo largo de estos tres años.

b) Analizar el comportamiento de las cuentas por cobrar que generan flujos de efectivo derivados de acuerdos contractuales (inicial y cuotas a largo plazo), en el cual la compañía recibe el importe de las propiedades vendidas en periodos que superan los 5 años. Por lo que se evaluará el mantenimiento del activo para poder cobrar los flujos de efectivo contractuales.

c) Describir la situación actual del sector, así como determinar el grado de conocimiento y las expectativas generadas por la aplicación de la NIIF 15, con la finalidad de complementar el análisis cuantitativo.

d) Evaluar la proporción de las cobranzas dudosas de la empresa y el impacto que tendrían estas en la implementación de la NIIF 9, pues, bajo este nuevo enfoque se está incorporando la totalidad del universo de saldos por cobrar comerciales no deteriorados en el cálculo de la provisión, como estimados para prever posibles deterioros futuros. 
e) Visualizar la pérdida del alcance de la NIC 39 en la compra de activos de la empresa a través del arrendamiento financiero.

El ya no uso de la NIC 39 abre paso a la NIIF 7, ya que esta nueva norma busca asegurar que los arrendatarios y arrendadores proporcionen información relevante que represente fielmente las transacciones.

f) Evaluar el efecto de la aplicación de NIIF 9, NIIF 15 y NIIF 16, en los indicadores financieros de las empresas del sector construcción e inmobiliario.

g) Identificar el desarrollo de la empresa en el futuro, para esto se realizará la proyección de los Estados Financieros Separados del 2018 al 2020, tomando como año base el 2017. Esto nos dará un mayor alcance de interpretación sobre el horizonte de sus actividades al largo plazo.

h) Dar soluciones o recomendaciones que se podrían implementar en la empresa, con la intención de mejorar sus logros y disminuir sus limitaciones, los cuales se traducirán en mejores rendimientos económicos, alcanzar una buena estructura de financiamiento y a bajo costo financiero. 


\section{CAPÍTULO III: MARCO METODOLÓGICO}

\subsection{Metodología de recolección de la información}

\section{Describir la forma cómo se ha recolectado la información:}

El caso de investigación los Portales S.A. la información financiera recolectada está en base a los informes auditados y estados financieros 2015-2017 que está en libre disposición para el público en general y colocado en la página web de la SMV. Otra fuente que nos ayudó a contribuir para la elaboración de este trabajo, fueron los trabajos de las empresas Equilibrium y Class \& Asociados S.A. y, por último, la memoria anual de los Portales S.A. del 2016 y 2017.

La técnica de información que se utilizó es la siguiente:

Técnica documental o bibliográfica: Se buscó libros y tesis relacionado sobre la teoría de la información financiera, páginas web de la portada de los Portales S.A. que nos ayudó a obtener mayor información acerca de su origen y sus proyectos futuros, entre otros.

Asimismo, fueron fuentes de información, las páginas web de instituciones como CAPECO, Minsur, MEF, así como también artículo de noticias que nos ayudó a proyectar o estimar el crecimiento de sus ingresos de la Empresa Los Portales S.A. de cada sector. Análisis documentario: Se revisaron las Normas Internaciones de Información Financiera de la página web del MEF (NIIF 16, NIIF 9 y NIIF 15), que serán necesarias para la aplicación de las proyecciones de los estados financieros y realizar las conclusiones respectivas.

Asimismo, se realizó una encuesta a profesionales de contabilidad, de algunas empresas constructoras e inmobiliarias, con la finalidad de describir la situación actual del sector, y determinar el grado de conocimiento y expectativas generadas por la aplicación inicial de las NIIF en mención, complementado los resultados cuantitativos obtenidos. 


\subsection{Metodología de análisis de la información}

\section{Describir la metodología seguida en el análisis de la información:}

De acuerdo a los informes auditados y estados financieros 2015- 2017 de la empresa Los Portales S.A. se concluyó que las cuentas contables no han variado, lo cual nos ayuda o facilita comparar la variación de cada año, así como el análisis respectivo de la información financiera y las proyecciones de los estados financieros de los años 2018, 2019 y 2020 tomando como referencia el año 2017.

Para el procesamiento y análisis de datos, no se realizó mediante algún software de gestión. Para ello, se llevó a cabo el registro de los datos obtenidos de los EE.FF. en hojas de Excel, estas hojas dinámicas sirvieron para la elaboración de tablas y gráficos que ayudaron a un mejor entendimiento del presente trabajo.

La proyección de los estados financieros fue a través de un análisis de regresión de las ventas y de la elaboración de un cuadro de variables que nos permitieron la proyección del Estado de Situación Financiera. Estas proyecciones se han validado mediante el juicio de expertos, dado que se sometió a la revisión y evaluación de dos profesionales de la Facultad de Ciencias Económicas y empresariales, pertenecientes al área de contabilidad. 


\section{CAPÍTULO IV: ANÁLISIS Y PRESENTACIÓN Y DISCUSIÓN DE RESULTADOS}

\subsection{Análisis de la información}

\section{Activo y liquidez}

\subsection{Presentación y discusión de resultados}

Finalizando el periodo 2015, los activos de la empresa Los Portales S.A. totalizaron un importe de S/ 1,514 millones incrementándose en un 24\% con respecto al año anterior. Las partidas que hicieron que se incrementaran son principalmente efectivo $\mathrm{y}$ equivalentes de efectivo con un aumento de $196 \%$ con respecto al año anterior, otra partida que ayudó a elevar los activos fueron las cuentas por cobrar comerciales parte no corriente con un $71.38 \%$, esta variación ha sido principalmente por el aumento de las letras por cobrar de ese año. En el periodo 2016, los activos de Los Portales S.A. sumaron un importe de S/ 1,579 millones, que refleja un incremento de 4.3\% con relación al año anterior, estas partidas que influenciaron fueron las cuentas por cobrar comerciales tanto corriente como no corriente, ambas se incrementaron en un $37.2 \%$.

Otra partida que participó en dicho aumento fue la cuenta propiedad de inversión, debido a que mantienen terrenos sin uso que no serán vendidos ni desarrollados en el corto plazo, generando un incremento en la plusvalía de estos terrenos.

Por otro lado, al cierre del año 2017, los activos de Los Portales S.A. totalizaron un importe de S/ 1,642 millones, incrementándose en un 4.4\% con respecto del año anterior. Las partidas que más impactaron en dicho aumento fueron las cuentas por cobrar comerciales tanto corrientes, no corrientes e inventarios. Las cuentas por cobrar comerciales se incrementaron en 30.5\%, debido a las nuevas ventas del 2017 y los inventarios aumentaron en $9.3 \%$ respecto al año anterior debido a la generación de más terrenos en desarrollo y más proyectos terminados.

A nivel cuantitativo, la cuenta que más impactó en la variación de los activos entre los años 2015 y 2017 fue la partida inventarios, que se muestra en el gráfico a continuación: 
Figura 8.1

Composición de los inventarios de los años 2015-2017

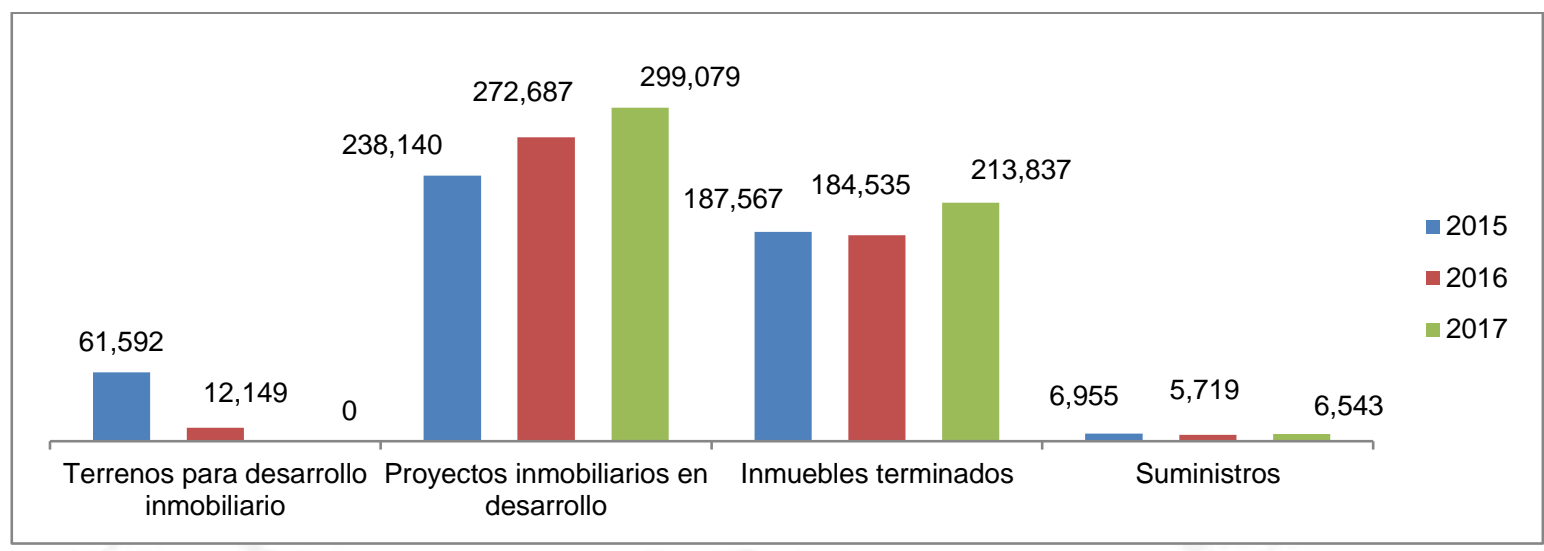

Fuente: Los Portales (2017).

Elaboración propia

El rubro efectivo y equivalente de efectivo se redujo en $29.3 \%$ y $37.37 \%$ por los años 2016 y 2017 respectivamente, esto debido a la disminución de los fondos mutuos que se mantenían en los años 2015 y 2016 (más de S/ 20 millones), que fueron destinados al pago de amortizaciones de préstamos de corto plazo. El incremento de las ventas de los años mencionados, no han tenido efecto en el efectivo y equivalencia de efectivo de la compañía.

El rubro propiedad, planta y equipo reflejó un incremento promedio de $4 \%$ en el año 2016, con respecto al año anterior principalmente por el incremento de edificios y otras construcciones. En el año 2017, esta partida tuvo una reducción de $2.65 \%$ que obedece principalmente a que la compañía transfirió del rubro "propiedades, planta y equipo, neto" al rubro "propiedades de inversión, neto" un importe de aproximadamente S/ 136.4 millones correspondiente al valor de los terrenos y las obras en curso de un centro comercial ubicado en la ciudad de Arequipa, cuya construcción culminó en dicho año.

Con respecto, al análisis de liquidez se aplicaron tres ratios, los cuales se detallan a continuación:

El ratio de liquidez general nos arrojó que la empresa en el 2015 tenía un índice de 1.38 y éste fue evolucionando en el 2016 hasta alcanzar 1.41, en el año 2017 éste ratio se estableció en 1.44, lo cual indica que la empresa tiene suficiente activo corriente para poder asumir sus deudas a corto plazo. Tal es así que, por cada sol de deuda de corto 
plazo, la empresa tiene S/ 1.44 para poder cubrir sus deudas, por lo que la empresa no tendría problemas de liquidez.

Otro ratio que se refleja en el cuadro de indicadores de liquidez es la prueba ácida, sin embargo, éste ha ido disminuyendo ligeramente, ya que en el 2015 fue 0.53 y en el 2017 alcanzó a 0.52, lo que indica que la empresa tendría relativos problemas de liquidez si es que no cuenta con sus inventarios, tal es así que, por cada S/ 1.00 de deuda corriente, la empresa tendría a penas $\mathrm{S} / 0.52$ para poder hacer frente a dicha deuda. Con respecto a la prueba defensiva, éste ratio arrojó 0.24 en el 2015 y en el 2017 en 0.11 , con lo cual la empresa no podría cubrir sus deudas urgentes solamente con su efectivo. Estos análisis son un resumen del cuadro que se muestra a continuación:

Figura 8.2

Indicadores de liquidez de los años 2015-2017

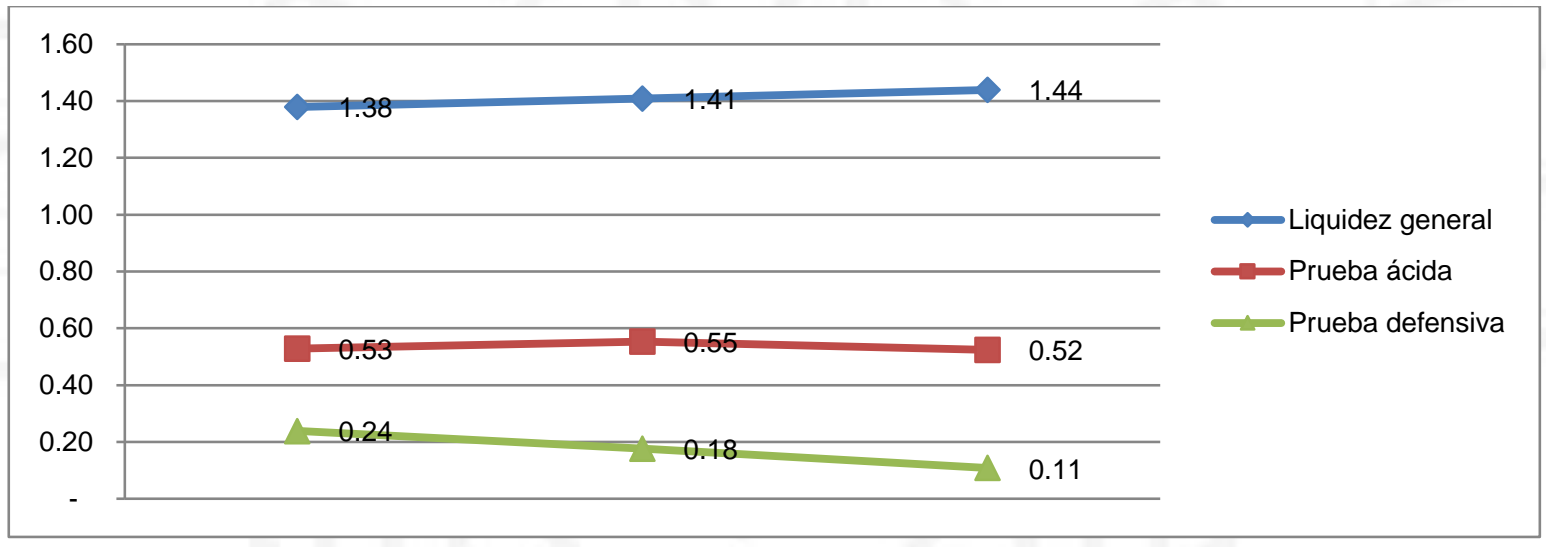

Fuente: Los Portales (2017).

Elaboración propia

Por otro lado, el capital de trabajo aumentó año tras año, debido a que se incrementaron las partidas de los activos más importantes del giro del negocio como son las cuentas por cobrar comerciales y el inventario, cuentas que están relacionadas directamente con el rubro de venta inmobiliaria. Esta apreciación se refleja en el cuadro de evolución del capital de trabajo. 
Figura 8.3

Evolución del capital de trabajo 2015-2017

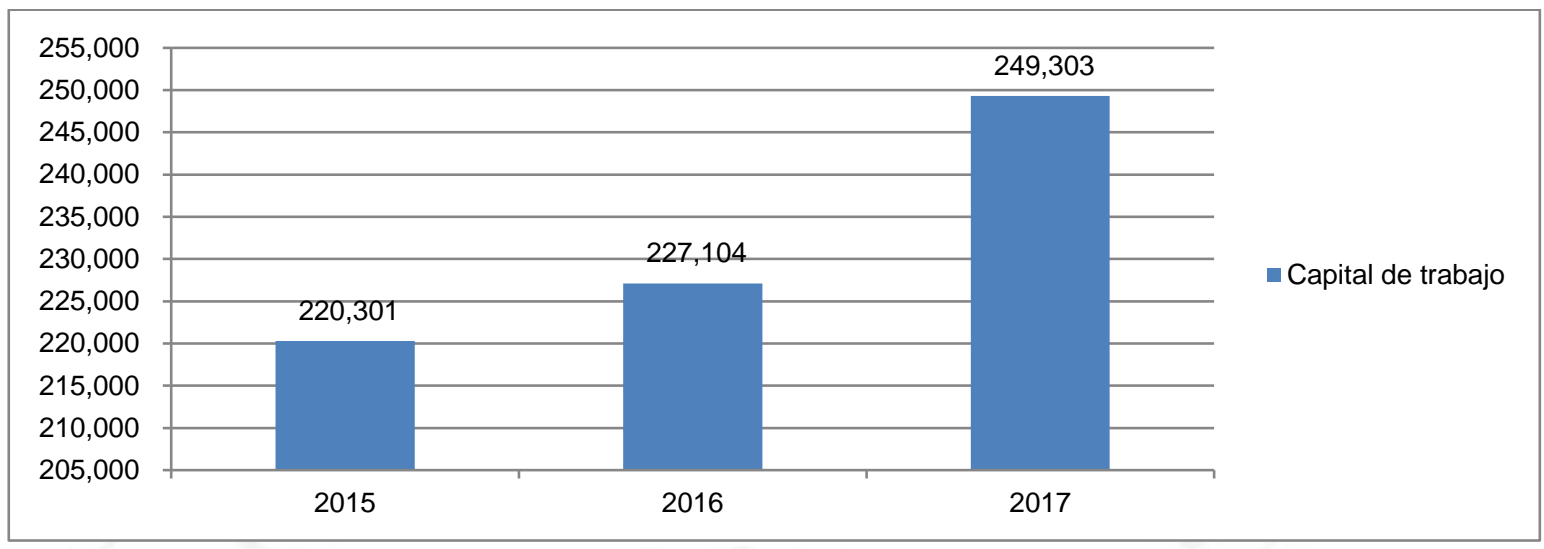

Fuente: Los Portales (2017).

Elaboración propia

\section{Estructura financiera y solvencia}

Para el análisis del endeudamiento de la empresa se aplicaron los ratios relacionados al grado de endeudamiento y endeudamiento patrimonial. El primero arrojó que la empresa en el 2015 tenía un endeudamiento del 75\% del total de la inversión, mientras que en el 2017 se trató de reducir ese grado de apalancamiento llegando a 72\%, es decir la deuda con terceros es un importante apoyo para el crecimiento de la empresa, sin embargo, éstas altas deudas nos indica que la empresa está funcionando con una estructura financiera riesgosa.

Por parte del endeudamiento patrimonial, podemos ver que la empresa tiene ratios sobre el patrimonio de 3.09 para el 2015, 2.69 para el 2016 y para el 2017 bordeó los 2.36, lo cual indica que los pasivos superan en más de 2 veces al patrimonio de los socios. Con esto podemos definir, que se está perdiendo autonomía financiera en el negocio, ya que las deudas fueron de gran importancia sobre las inversiones de la empresa.

Para profundizar con el análisis se va a desarrollar acerca de las principales cuentas de los pasivos. La partida de las obligaciones financieras es la que tuvieron mayor importancia, ya que en el corto y largo plazo superaron el $44 \%$ en el $2015,40 \%$ en el 2016, mientras que en el 2017 éstas cayeron alrededor del 38\%. La disminución de los préstamos bancarios en los años 2016 y 2017 se debió principalmente a que la empresa emitió bonos corporativos y papeles comerciales para que sean adquiridos en el exterior. 
Dicha emisión de bonos fue una estrategia financiera con el objetivo de pagar principalmente los préstamos bancarios y en consecuencia reducir los costos financieros, es por ello que la emisión de bonos ha seguido incrementándose año tras año.

Por ejemplo, en el 2016 se incrementó en un $65.33 \%$ en relación del año anterior, mientras en el 2017 se incrementó moderadamente en un $19.44 \%$ con respecto al 2016 , con lo cual se denota claramente una estrategia definida de la empresa para reducir sus costos financieros. "En relación al rango de la tasa del año 2017 de los bonos corporativos y papeles comerciales colocados en dólares oscilaron entre 5,5\% y $9 \%$ y para bonos corporativos y papeles comerciales colocados en soles oscilaron entre 5,64\% y 7,05\%." (SMV, 2018, p.20)

Tabla 8.1

Emisión de bonos corporativos y papeles comerciales del año 2017

\begin{tabular}{|c|c|c|c|c|c|c|c|c|c|}
\hline Instrumento & Oferta & Programa & $\begin{array}{c}\mathbf{N} \\
\text { emisión }\end{array}$ & $\begin{array}{l}\text { Serie/ } \\
\text { Clase }\end{array}$ & Moneda & $\begin{array}{l}\text { Monto de } \\
\text { colocación } \\
\text { moneda } \\
\text { original } \\
\text { (en miles) }\end{array}$ & $\begin{array}{c}\text { Monto de } \\
\text { colocación } \\
\text { S/ 000 }\end{array}$ & $\begin{array}{c}\text { Fecha de } \\
\text { emisión } \\
\text { S/ } 000\end{array}$ & $\begin{array}{c}\text { Fecha de } \\
\text { vencimiento } \\
\text { S/ } 000\end{array}$ \\
\hline $\begin{array}{c}\text { Bonos } \\
\text { corporativos }\end{array}$ & Privada & Segundo & $\begin{array}{c}1,2,3 \mathrm{y} \\
4\end{array}$ & única & US\$ & 21,989 & 71,354 & $15 / 02 / 2017$ & $15 / 02 / 2022$ \\
\hline $\begin{array}{c}\text { Bonos } \\
\text { corporativos }\end{array}$ & Privada & Segundo & 5,6 y 7 & única & US\$ & 11,895 & 38,599 & $15 / 06 / 2017$ & $15 / 06 / 2022$ \\
\hline $\begin{array}{c}\text { Bonos } \\
\text { corporativos }\end{array}$ & Privada & Tercero & $1 \mathrm{y} 2$ & única & US\$ & 8,057 & 26,145 & $15 / 11 / 2017$ & $15 / 11 / 2022$ \\
\hline $\begin{array}{c}\text { Bonos } \\
\text { corporativos }\end{array}$ & Pública & Primero & 1 & única & US\$ & 6,681 & 21,680 & $20 / 12 / 2017$ & $20 / 12 / 2020$ \\
\hline $\begin{array}{c}\text { Papeles } \\
\text { comerciales }\end{array}$ & Pública & Primero & 9 & B & $\mathrm{S} /$ & 20,000 & 20,000 & $24 / 02 / 2017$ & 19/02/2018 \\
\hline $\begin{array}{c}\text { Papeles } \\
\text { comerciales }\end{array}$ & Pública & Primero & 10 & A & $\mathrm{S} /$ & 16,672 & 16,672 & $12 / 04 / 2017$ & 07/04/2018 \\
\hline $\begin{array}{c}\text { Papeles } \\
\text { comerciales }\end{array}$ & Pública & Segundo & 1 & A & $\mathrm{S} /$ & 20,000 & 20,000 & $29 / 08 / 2017$ & $24 / 08 / 2018$ \\
\hline $\begin{array}{c}\text { Papeles } \\
\text { comerciales }\end{array}$ & Pública & Segundo & 3 & A & $\mathrm{S} /$ & 25,000 & 25,000 & 06/12/2017 & $01 / 12 / 2018$ \\
\hline
\end{tabular}

Fuente: SMV (2017)

Elaboración propia

Dentro de los pasivos, el que ocupa el primer grado de importancia son los rubros de otros pasivos financieros, que representan en un promedio del $41 \%$ del total de inversión en los tres periodos. Este rubro está compuesto principalmente por bonos (49.75\% del total corresponde a préstamos bancarios, préstamos de terceros $\mathrm{y}$ arrendamientos).

Por consiguiente, tenemos los préstamos bancarios que dentro de la cuenta de otros pasivos financieros representan entre 28\%, 23\% y 24\% de los años 2015, 2016 y 
2017 respectivamente. Como se puede ver, estos préstamos han estado disminuyendo moderadamente debido a que la empresa ha estado pagando sus obligaciones con la partida efectivo y equivalencia de efectivo, por ejemplo, estos préstamos se redujeron en el 2016 en un $22.87 \%$ con respecto al 2015, mientras que en el 2017 en relación al 2016 sólo se incrementó en un $2.43 \%$.

Es por ello, que en el anexo 1 se puede reflejar que los gastos financieros han estado disminuyendo producto de esa reducción de deuda con bancos. Éstos préstamos tienen una tasa de interés que oscilan en un $7.12 \%$ frente a una tasa del $5 \%$ con respecto a los bonos.

Otra cuenta dentro las obligaciones financieras se encuentran los préstamos con terceros cuya participación son 36,70\%, 20.07\% y 7.93\% en los periodos 2015, 2016 y 2017 respectivamente. Sin embargo, han estado disminuyendo, por ejemplo, en el 2016 disminuyó en un $48.26 \%$ con respecto al año anterior, mientras en el 2017 en un $61.56 \%$ Estos préstamos están compuestos principalmente por préstamos de personas naturales y jurídicas.

Por último, están los arrendamientos financieros que tiene una participación no tan importante dentro de la partida obligaciones financieras, ya que en el 2015 éstas eran $4.54 \%$, en el 2016 eran $3.59 \%$ y, por último, en el 2017 fueron de $2.34 \%$ del total de pasivos. Estos arrendamientos generan intereses por los locales y fluctúan entre el $1 \%$ al $9 \%$.

A continuación, se mostrará los componentes de los pasivos corriente y no corriente para obtener mayor conocimiento de su participación de cada uno de ellos.

\section{Figura 8.4}

Composición de deuda de los años 2015-2017

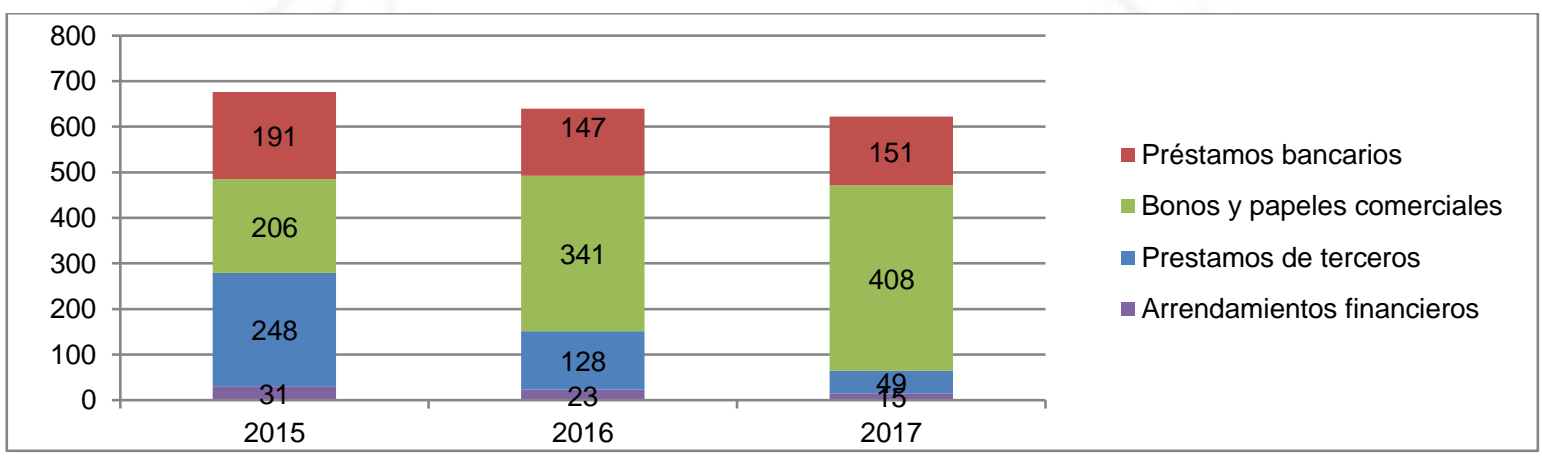

Fuente: Los Portales (2017).

Elaboración propia 
En relación, a las cuentas por pagar comerciales representan en segundo grado de importancia en relación a los pasivos (recordemos que otros pasivos financieros son el primer grado de importancia). Estas cuentas representan en un promedio de $22 \%$ para los tres años en estudio. Este tipo de pasivos corresponden principalmente a las adquisiciones de terrenos, materiales suministros y otros servicios. Asimismo, dentro de los contratos de compra y venta de terrenos, dichos contratos no generaron intereses para la empresa, esto se debe a que el principal vendedor de los terrenos es el Estado, que cobra mínimos intereses, y esto, con la condición de que la empresa se comprometa a desarrollar nuevos polos urbanísticos.

La otra fuente de financiamiento es la de patrimonio de los accionistas, que representan entre el $27 \%$ y $30 \%$ del total de la inversión en la empresa en los últimos años. Con lo cual se ve el gran peso que tiene el pasivo con terceros (70\%). La principal cuenta dentro de la partida del patrimonio son las utilidades por distribuir (siendo más de la mitad del patrimonio).

El ratio de cobertura de activos fijos ha estado ligeramente constante, motivo a que el activo fijo y el patrimonio con relación a los años no se ha ido incrementando.

Por último, tenemos el ratio de cobertura de intereses que fue disminuyendo gracias a que la empresa ha ido amortizando las obligaciones de corto plazo (préstamos bancarios).

Los dos ratios mencionadas se mostrarán a continuación:

Figura 8.5

Ratios de solvencia de los años 2015-2017

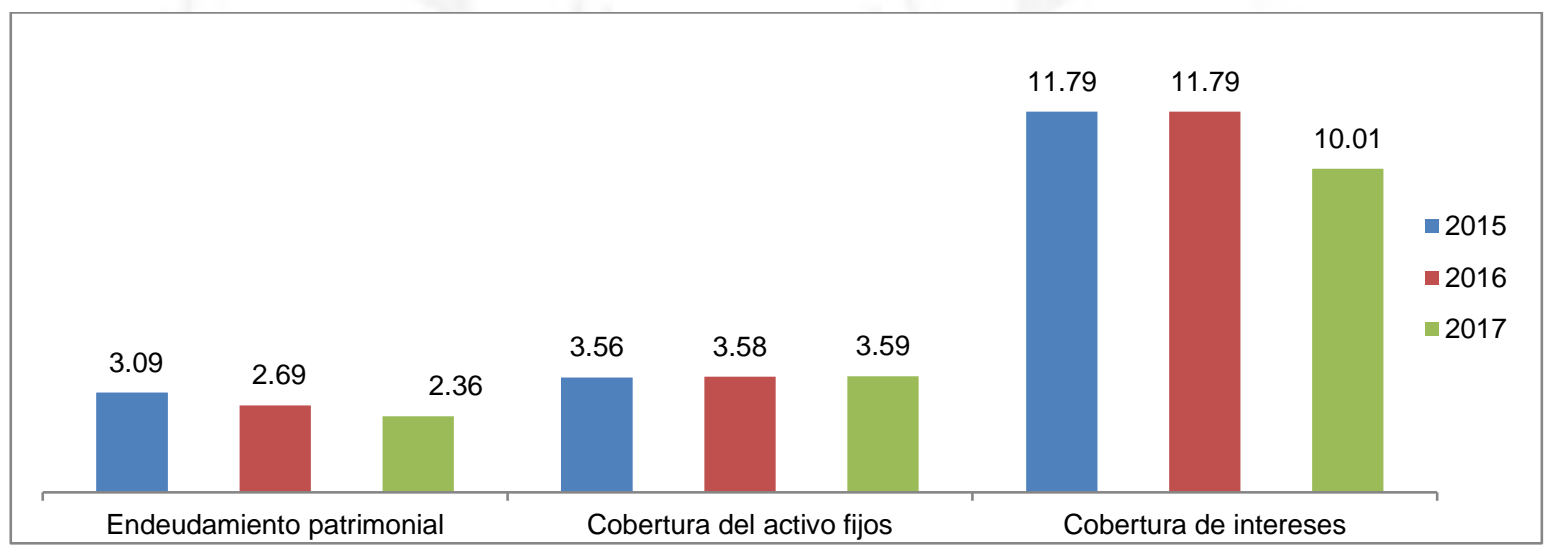

Fuente: Los Portales (2017).

Elaboración propia 


\section{Ratios de gestión}

Se aplicaron tres ratios para demostrar la eficiencia de cada una de las áreas de la empresa, así tenemos:

Rotación de cuentas por cobrar: Se puede observar que la empresa en el 2015 se demoraba en cobrar sus ingresos en un promedio de 208 días, luego este periodo fue aumentando hasta llegar a 275 días en el año 2017. Lo cual refleja que la empresa está demorando cada vez más en el cobro de sus cuentas. Esta demora, podría complicar a la liquidez del negocio o se puede deducir de lo anterior, que el área de cobranza de la empresa está perdiendo eficiencia al momento de convertir en efectivo dichas cuentas, es por ello que la empresa estaría perdiendo eficiencia en la gestión del área de cobranzas.

Hay que recordar que la empresa vende propiedades por lo que generalmente los periodos de cobranzas de este sector son relativamente altos. Las cobranzas por las propiedades son por lo general a largo plazo y a través de títulos valores como las letras de cambio, por lo general, estas letras tienen una duración de 72 meses desde la firma del contrato.

Rotación de inventarios: Se puede denotar que el proceso de comprar y vender sus inventarios fue de 371 días en el 2015 y disminuyó hasta alcanzar el periodo de 365 días para el año 2017, lo cual refleja que la empresa está haciendo los esfuerzos por colocar con mayor velocidad sus inventarios. Estos inventarios están compuestos principalmente por terrenos, departamentos, y otros proyectos que se encuentran en proceso de construcción. Con esto se puede opinar, que la empresa mantiene una buena gestión en el área de ventas.

\section{Rotación de cuentas por pagar:}

Con respecto, al área de logística podemos ver que la empresa está negociando con sus proveedores en la ampliación de plazos de pago, esto sería beneficioso, ya que estos proveedores reducirían la necesidad de nuevos financiamientos de la empresa. La empresa en el 2015 demoraba en pagar a proveedores en un promedio de 237 días, mientras que en el año 2017 aumentó a 258 días, por lo que se espera que estos plazos de pago se sigan elevando. En resumen, se puede decir que el área de logística está reflejando una buena gestión porque cada vez está adquiriendo créditos a más plazos y con un costo financiero barato. 
Figura 8.6

Ratios de gestión de los años 2015-2017

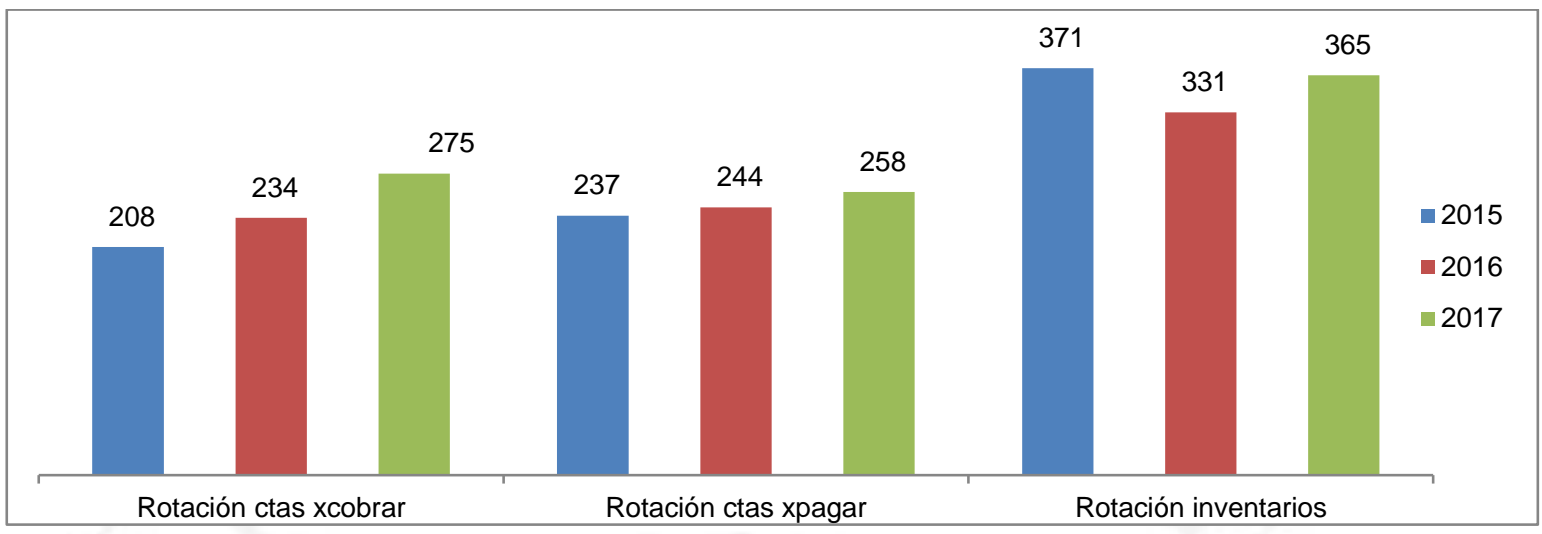

Fuente: Los Portales (2017).

Elaboración propia

\section{Ratios de rentabilidad}

Al cierre de cada año, los ingresos de Los Portales S.A. han aumentado sus ventas, por ejemplo, los ingresos del 2016 se incrementaron en un 5.4\% gracias a la venta del rubro inmobiliario y estacionamiento. Sin embargo, en el año 2017 se incrementó en un 0.6\% que es un porcentaje bien reducido con respecto al año anterior. Este poco incremento fue debido a que el sector construcción (inmobiliario) no creció como se esperaba, principalmente fue por el impacto del Fenómeno del Niño Costero y temas de corrupción como el caso de Odebrecht. No obstante, el impulso de ventas fue apoyado gracias al rubro estacionamientos.

Por otro lado, los costos se mantuvieron casi constantes, gracias a una eficiente política de estructura de sus costos. En esta partida los costos que varían son principalmente las materias primas, la mano de obra directa y los servicios encargados a terceros.

El comportamiento de estos costos lo veremos en el margen bruto que viene a continuación:

La empresa tiene un margen bruto en promedio de los tres años de $32 \%$, lo cual significa que la empresa tiene un buen sistema de control de costos, lo cual garantiza la eficiencia en el uso de sus componentes del costo.

El único rubro que redujo sus ventas y también su utilidad bruta, es el segmento hotelero, debido a que hay demasiada competencia. Asimismo, las remodelaciones que 
han estado haciendo en el hotel Country Club afectan al margen de la empresa. Recordemos que el Country Club es su principal hotel que le genera mayores ingresos.

Para mayor entendimiento de lo explicado líneas arriba, se ha realizado un gráfico de los segmentos de la empresa Los Portales S.A.:

Figura 8.7

Utilidad bruta de los años 2015-2017

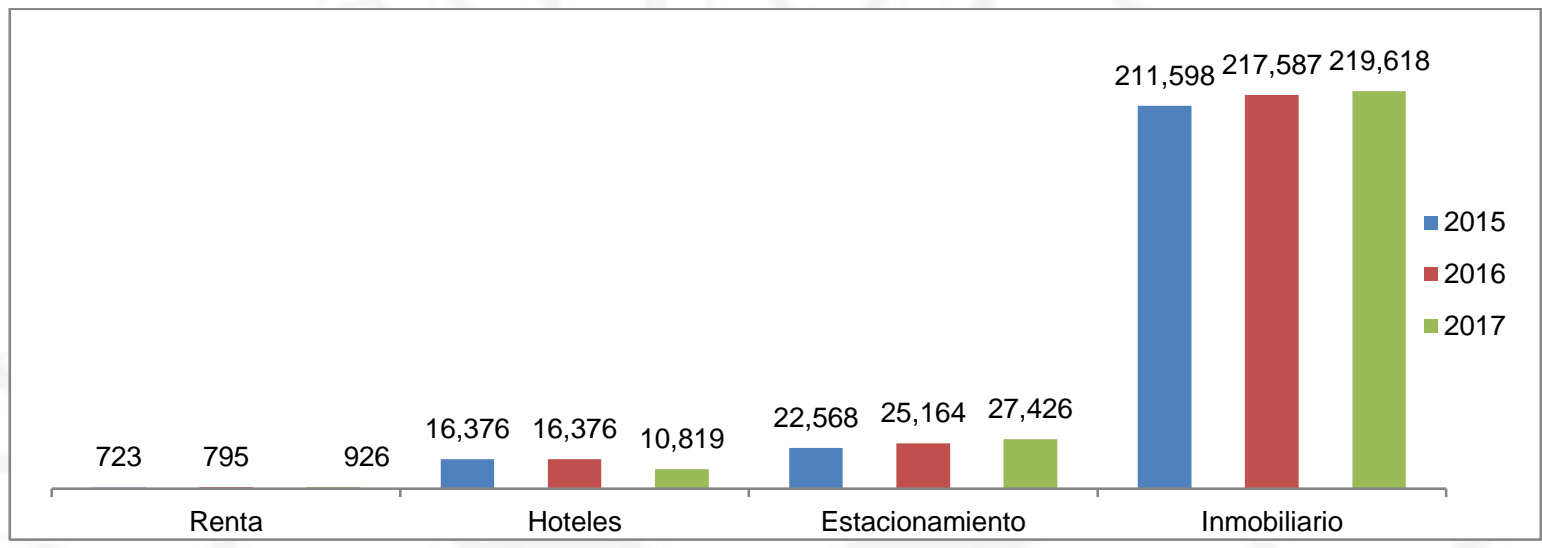

Fuente: Los Portales (2017).

Elaboración propia

Con respecto a los gastos operativos todos se mantienen constantes, ya que éstos llegan a ser el 16\% del total de las ventas en promedio de los tres años, solamente en los gastos de ventas hay partidas que sufren variación como son la publicidad y comisiones de los vendedores.

Con esto vemos claramente que la empresa arrojó un margen operativo del negocio de $16 \%$, es decir, no se incluyen los gastos financieros y los gastos por diferencia de cambio.

Con respecto al margen operativo, éste se ha mantenido dentro de los parámetros planeados por la empresa, ya que éste representa en un promedio de $16 \%$ de las ventas en los tres años de estudio.

La empresa tiene ganancias por este efecto cambiario, que viene a ser por la venta de la cartera inmobiliaria, estas ganancias cambiarias provienen de las cuentas por cobrar comerciales. Las cuentas por cobrar son principalmente letras firmadas en dólares y por un periodo promedio de 5 años, por lo cual, ante la apreciación del dólar frente al sol, tendrá un efecto de ganancia por diferencia de cambio de esta partida 
Por otro lado, los gastos financieros han estado disminuyendo, gracias a que la empresa ha estado cumpliendo con sus obligaciones financieras principalmente préstamos bancarios. Dicha reducción de gastos financieros también es consecuencia del repago de las obligaciones financieras con dinero proveniente de la emisión de bonos.

Finalmente, el margen neto de la empresa ha mostrado una recuperación, ya que en el año 2015 este margen era de $7.40 \%$ y finalizó en el año 2017 con $10.33 \%$ como se muestra en el gráfico líneas abajo. Además, se puede mostrar que ésta subida del margen neto fue gracias a que está respaldada por el control de los costos, la eficiencia de los gastos, por la caída de los gastos financieros y por las ganancias de diferencia de cambio.

Figura 8.8

Márgenes bruto, operativo y neto de los años 2015-2017

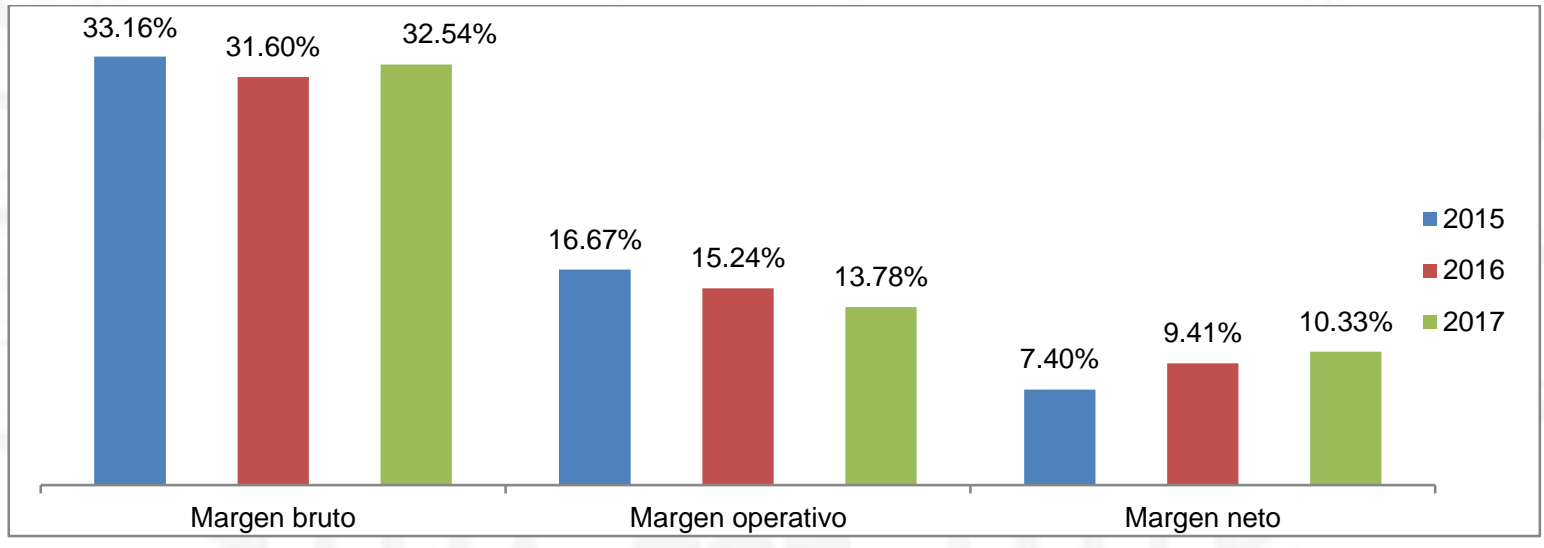

Fuente: Los Portales (2017).

Elaboración propia

Con respecto al ROE, podemos inferir que la empresa está recuperando las rentabilidades para los accionistas, tal es así, que en el año 2015 el rendimiento del accionista era de $14.34 \%$. A consecuencia del aumento de la utilidad neta aumentó en el pasivo del 2017, éste ROE llegó a 16.04\%, por lo que la empresa está mejorando la expectativa de rendimientos por parte de los socios. También se puede comentar que por cada sol que invierte el accionista, éste llega a ganar S/ 0.16, y por el tamaño del negocio, esta rentabilidad llega a ser importante.

Por otro lado, el ROA representó en el 2015 una tasa de rendimiento de $3.51 \%$ y posteriormente ésta tasa llegó a $4.78 \%$ en el 2017 , con lo que se refleja en el gráfico una mejora en la eficiencia del uso de los activos, es decir, que los activos están recuperando en la generación de utilidades en comparación de años anteriores donde el ROA llegaba hasta en un $3 \%$. 
Figura 8.9

Evolución de indicadores de rentabilidad de los años 2015-2017

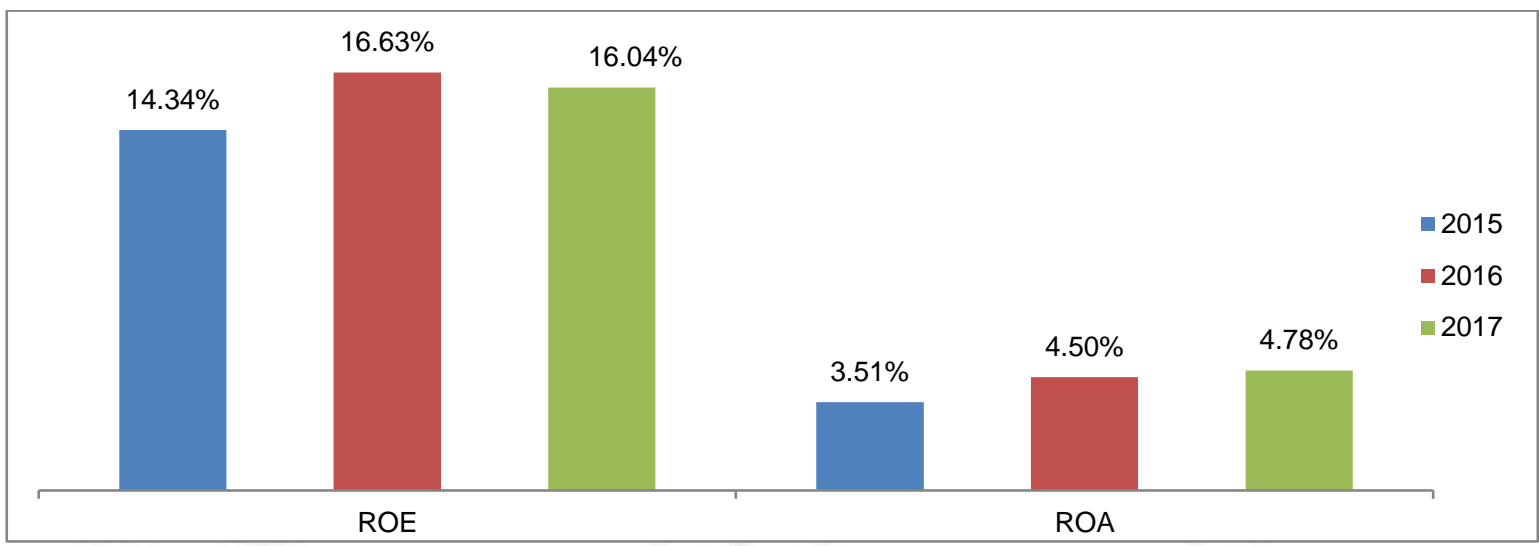

Fuente: Los Portales (2017).

Elaboración propia

\section{Análisis comparativo del sector inmobiliario: Benchmarking}

Como se mencionó el sector inmobiliario de la empresa Los Portales S.A. le generó a la compañía un promedio de $82.78 \%$ de ingresos en el periodo 2015 - 2017, es por ello que se ha tomado el segmento inmobiliario para comparar los ratios financieros con empresas del sector.

A continuación, se realizará una comparación con las empresas competidoras de Los Portales S.A.:

Al cierre del 2015, los activos de la empresa Los Portales S.A. totalizaron en S/ 1,337 millones, Inversiones Centenario fue S/ 2,120 millones y Ciudaris Consultores Inmobiliario fue S/ 71 millones. Asimismo, al cierre del año 2016, los activos de la empresa Los Portales S.A., totalizaron S/ 1,480 millones, Inversiones Centenario fue S/ 1,572 millones, mientras que Ciudaris fue apenas de S/ 105 millones.

Inversiones Centenario S.A.A. incrementó sus activos en $4 \%$ para el año 2016, mientras que para el año 2017 tuvo un incremento de $4.6 \%$.

La partida que más impactó para el aumento de dichos activos fue los inventarios, lo mismo que sucedió en el año 2017 y a menor medida en el 2015. Se hace hincapié, que es aceptable que ésta partida aumente por el giro del negocio (rubro inmobiliario). Asimismo, la partida está conformado principalmente por terrenos en reserva (terrenos que aún no tiene fecha para empezar el proyecto, sin embargo, se realizará en el corto 
plazo), suministros, terrenos en desarrollo y terrenos terminados, éstos dos últimos son los que tiene mayor participación de proporción con respecto a esta cuenta.

A continuación, se mostrará un cuadro de los componentes más importante de la partida del inventario del año 2017:

Figura 8.10

Composición de inventarios que más impactaron en el 2017

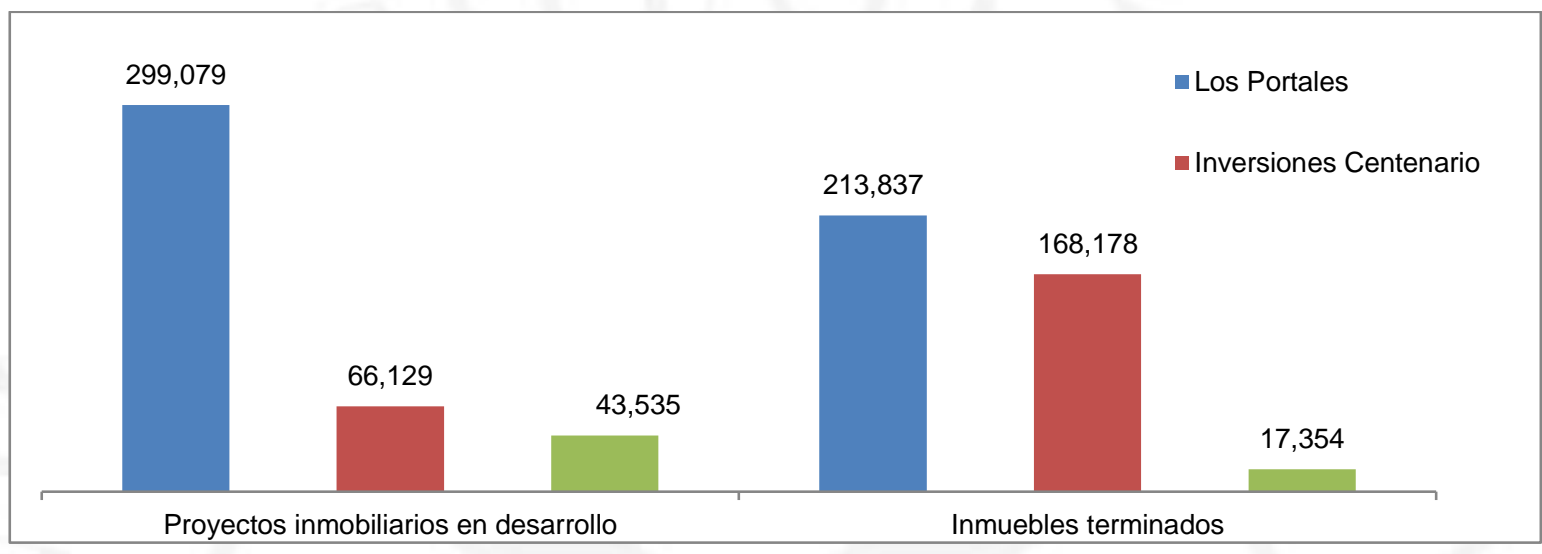

Fuente: Los Portales (2017).

Elaboración propia

Otra cuenta que también ayudó para el aumento del activo neto de Inversiones Centenario S.A.A. fueron las cuentas por cobrar comerciales corriente y no corriente. Por lo contrario, la empresa Ciudaris ha estado disminuyendo a pesar que sus ventas del 2015 al 2017 se han ido incrementado con mayor proporción.

Por ejemplo, en el gráfico de ratio de liquidez podemos observar que, en el 2017, las tres han tenido un nivel positivo, pero la que obtiene mayor activo con respecto a los pasivos es la empresa Ciudaris. Sin embargo, quien aumentó sus activos en mayor proporción fue la empresa Inversiones Centenario S.A., en comparación con la empresa Ciudaris y Los Portales S.A.

$\mathrm{Al}$ analizar la prueba ácida, estos índices fueron similares para las tres empresas. Por último, en la prueba defensiva, quien obtuvo mayor índice, fue la empresa Inversiones Centenario, debido a que ésta tiene un $11.4 \%$ de participación de la cuenta efectivo y equivalente de efectivo en relación a su total de activos. Mientras que las empresas Los Portales S.A. y Ciudaris arrojaron menores indicadores, debido a que su partida de efectivo y equivalencia de efectivo fueron usados para el pago de obligaciones financieras. 
Figura 8.11

Ratio de liquidez 2017

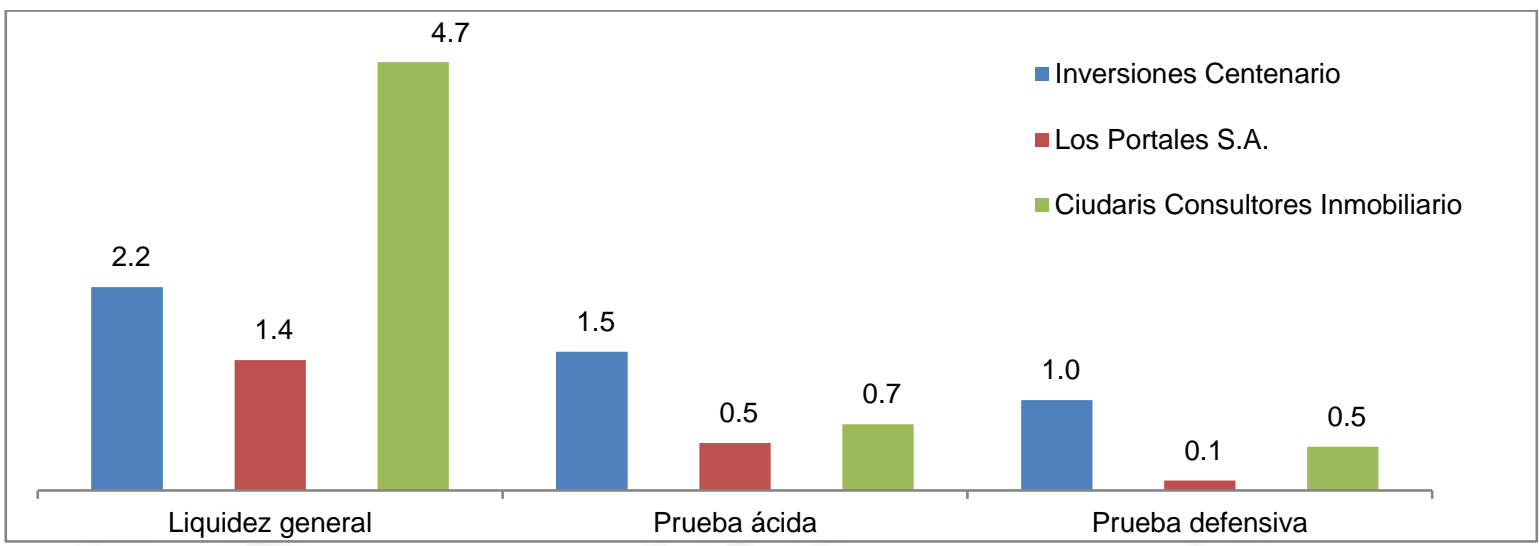

Fuente: Los Portales (2017).

Elaboración propia

Por otro lado, con respecto al capital de trabajo, las tres empresas tienen la capacidad de generar recursos para pagar sus obligaciones en el corto plazo, como se mostrará en el gráfico a continuación. Recordemos, que para las tres empresas en los años 2015 al 2017, las principales cuentas que ayudaron aumentar el capital de trabajo en las tres empresas fueron los inventarios y cuentas por cobrar comerciales.

Figura 8.12

Capital de trabajo del año 2017

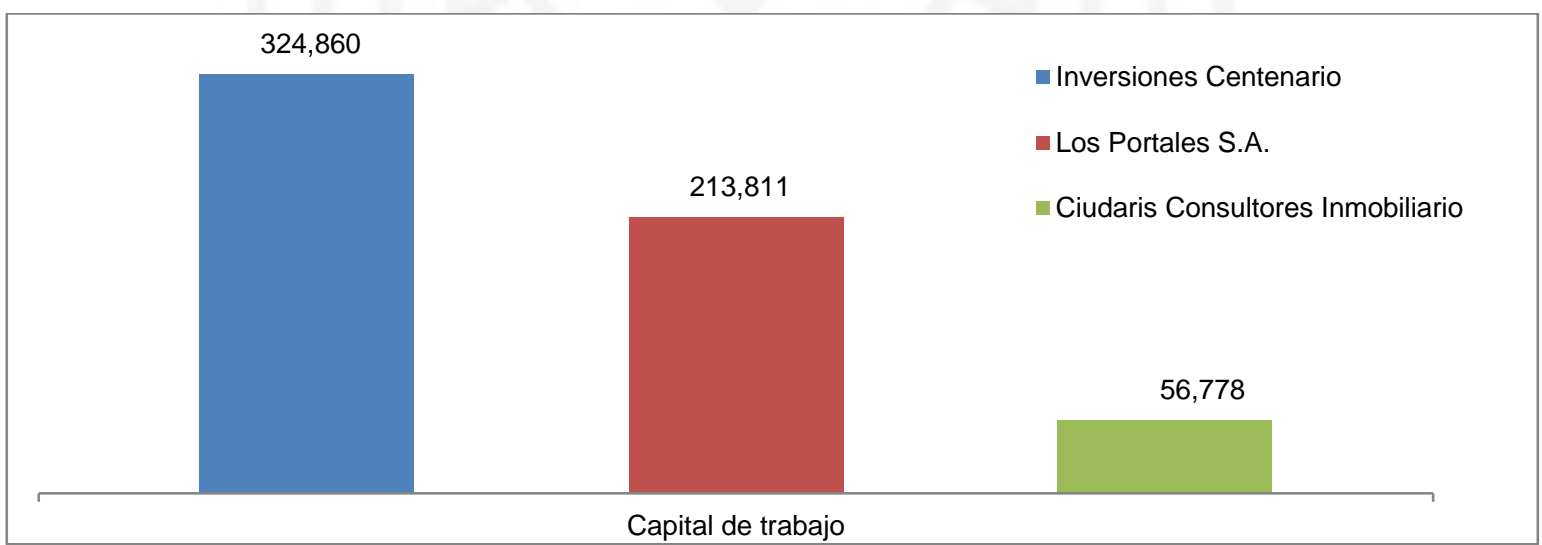

Fuente: Los Portales (2017).

Elaboración propia

\section{Estructura financiera y solvencia del sector venta inmobiliaria}

Las compañías principalmente respaldan sus activos a través de otros pasivos financieros (bonos corporativos, papeles comerciales entre otros) y a menor medida capital emitido 
en los años 2015 - 2017. Por ejemplo, las tres empresas están altamente endeudadas, tal como se muestra en el gráfico de ratios de solvencia. Vemos que las empresas se respaldan principalmente por los pasivos con terceros, siendo Los Portales S.A. la que posee mayor endeudamiento (70\% de la inversión total), seguido por Inversiones Centenario S.A.A. (50\% del total de sus activos).

Mientras, que en el ratio de cobertura de activo fijo, quién obtuvo mayor indicador fue Inversiones Centenario S.A.A., ya que su cuenta o partida de propiedad, planta y equipo no es una cuenta relevante para la compañía. Dicha empresa concentra sus inversiones en sus inventarios.

Con respecto a la cobertura de intereses, quien obtuvo un menor ratio fue Ciudaris, esto debido a que su EBIT fue negativo en el 2017.

Figura 8.13

Ratios de solvencia del año 2017

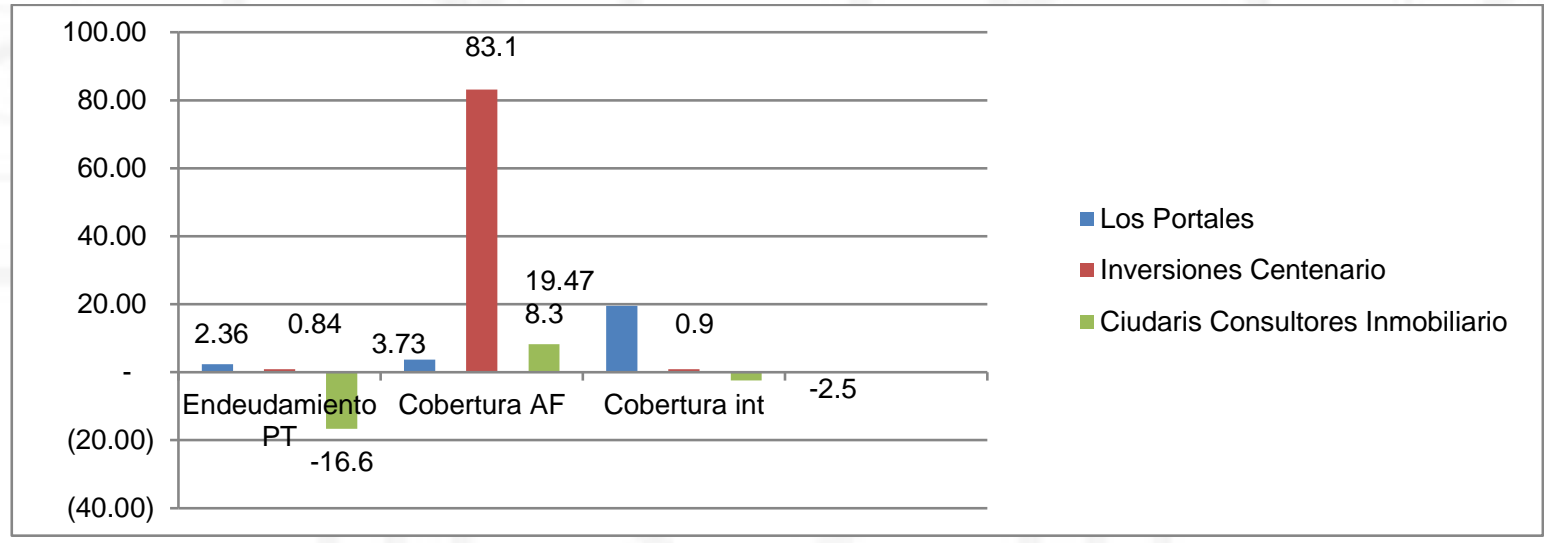

Fuente: Los Portales (2017).

Elaboración propia

\section{Generación, eficiencia y rentabilidad del sector venta inmobiliaria}

Al cierre del año 2015 y 2016 los ingresos han ido incrementando en las compañías inmobiliarias que han sido mencionados anteriormente. No obstante, al cierre del año 2017, la empresa Los Portales aumentó sus ingresos en un 7.9\% con respecto al año 2016. La empresa Ciudaris Consultores Inmobiliario e Inversiones Centenario crecieron en un $191 \%$ y $15 \%$ respectivamente.

La empresa que destacó por ingresos fue Ciudaris, pero sus altos costos y gastos de operación provocaron que la empresa arroje un EBIT negativo. 
Con respecto, al costo de ventas han estado constantes en relación de las ventas cada año, así como también el margen bruto.

Figura 8.14

Margen bruto de los años 2015-2017

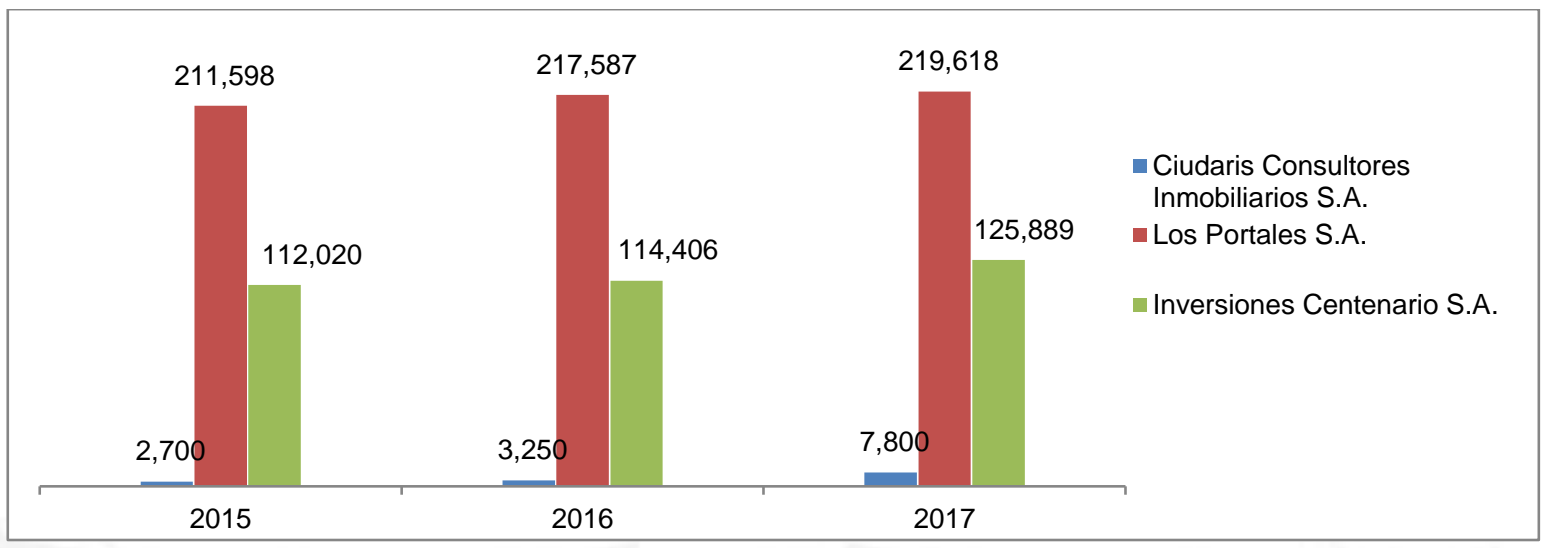

Fuente: Los Portales (2017).

Elaboración propia

Por otro lado, la utilidad neta ha sido positiva para las compañías Los Portales

S.A. e Inversiones Centenario, más no Ciudaris Consultores Inmobiliario. Como se va a mostrar a continuación:

Figura 8.15

Utilidad neta de los años 2015-2017

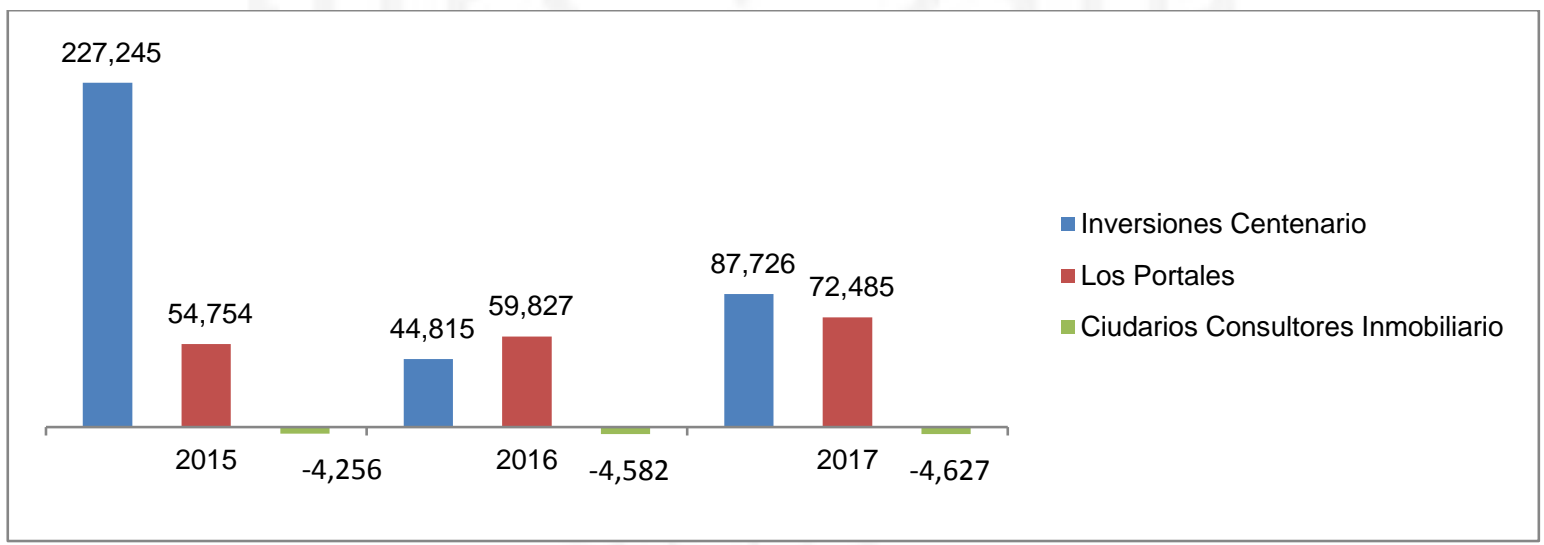

Fuente: Los Portales (2017).

Elaboración propia 


\section{Principales competidores:}

Tabla 8.2

Rubro inmobiliario

\begin{tabular}{|l|c|c|c|c|c|}
\hline \multicolumn{1}{|c|}{ Empresa } & $\begin{array}{c}\text { Ventas } \\
\mathbf{2 0 1 5}\end{array}$ & $\begin{array}{c}\text { Ventas } \\
\mathbf{2 0 1 6}\end{array}$ & $\begin{array}{c}\text { Ventas } \\
\mathbf{2 0 1 7}\end{array}$ & $\begin{array}{c}\text { Var. } \\
\text { Dic.16/Dic.15 }\end{array}$ & $\begin{array}{c}\text { Var. } \\
\text { Dic.17/Dic.16 }\end{array}$ \\
\hline Los Portales & 633,308 & 708,344 & 652,217 & $11.85 \%$ & $-7.92 \%$ \\
\hline Ciudaris Consultores & 12,429 & 14,405 & 41,952 & $15.90 \%$ & $191.23 \%$ \\
\hline Inversiones Centenario & 229,118 & 234,161 & 270,041 & $2.20 \%$ & $15.32 \%$ \\
\hline
\end{tabular}

Fuente: SMV (2015, 2016, 2017)

Elaboración propia

Podemos observar en el cuadro líneas abajo, que Los Portales tiene la mayor participación entre sus principales competidores, esto se debe a que el rubro inmobiliario aporta más a los ingresos de la empresa.

Figura 8.16

Participación del sector inmobiliario

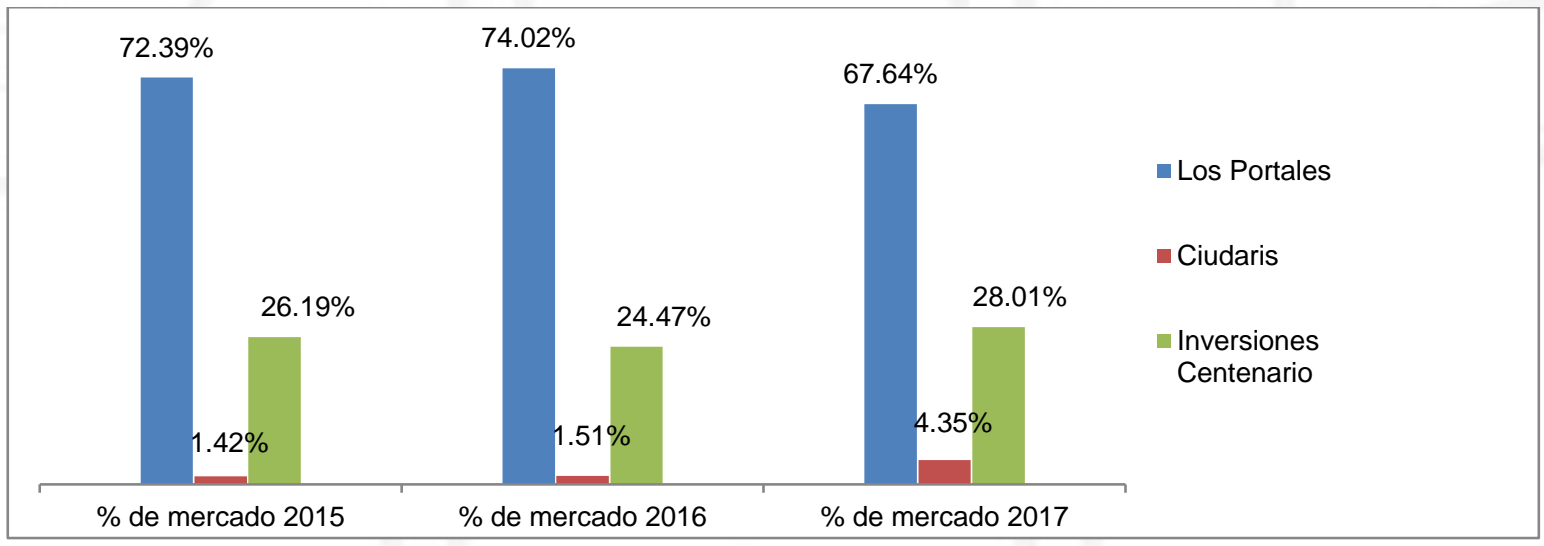

Fuente: SMV $(2015,2016,2017)$

Elaboración propia

Tabla 8.3

Rubro hotelero

\begin{tabular}{|l|c|c|c|c|c|}
\hline \multicolumn{1}{|c|}{ Empresa } & $\begin{array}{c}\text { Ventas } \\
\mathbf{2 0 1 5}\end{array}$ & $\begin{array}{c}\text { Ventas } \\
\mathbf{2 0 1 6}\end{array}$ & $\begin{array}{c}\text { Ventas } \\
\mathbf{2 0 1 7}\end{array}$ & $\begin{array}{c}\text { Var. } \\
\text { Dic.16/Dic.15 }\end{array}$ & $\begin{array}{c}\text { Var. } \\
\text { Dic.17/Dic.16 }\end{array}$ \\
\hline Inversiones Nacionales De Turismo S.A. & 219,495 & 236,541 & 251,987 & $7.8 \%$ & $6.5 \%$ \\
\hline Inversiones La Rioja S.A. & 134,222 & 181,800 & 162,140 & $35.4 \%$ & $-10.8 \%$ \\
\hline Nessus Hoteles Perú S.A. & 133,246 & 150,753 & 161,344 & $13.1 \%$ & $7.0 \%$ \\
\hline Los Portales S.A. & 48,476 & 49,861 & 46,168 & $2.9 \%$ & $-7.4 \%$ \\
\hline
\end{tabular}

Fuente: SMV (2015, 2016, 2017)

Elaboración propia 
En el rubro hotelero, quien tiene mayor participación entre sus principales competidores es la empresa Inversiones Nacionales de Turismo S.A. En el año 2018, esta empresa adquirió los hoteles Marriot, comprando más del 99\% de las acciones a la empresa Inversiones La Rioja S.A.

Figura 8.17

Participación del sector hotelero

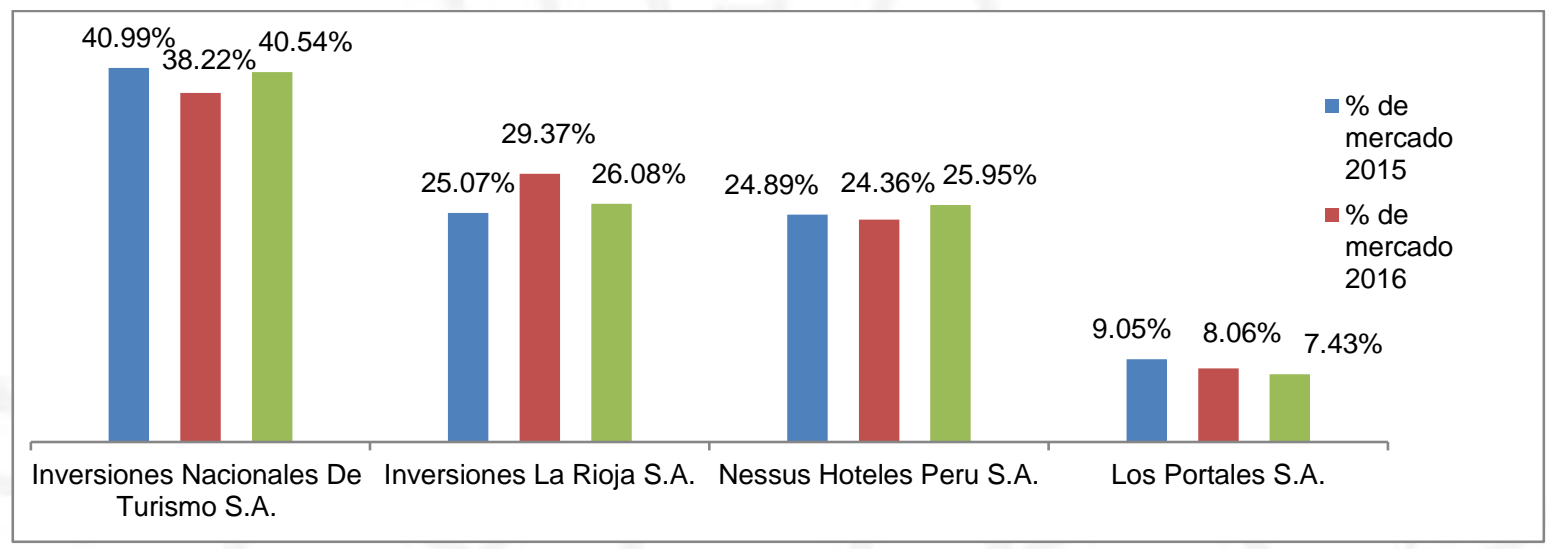

Fuente: SMV (2015, 2016, 2017)

Elaboración propia

Tabla 8.4

Rubro estacionamiento

\begin{tabular}{|l|c|c|c|c|c|}
\hline \multicolumn{1}{|c|}{ Empresa } & $\begin{array}{c}\text { Ventas } \\
\mathbf{2 0 1 5}\end{array}$ & Ventas 2016 & $\begin{array}{c}\text { Ventas } \\
\mathbf{2 0 1 7}\end{array}$ & $\begin{array}{c}\text { Var. } \\
\text { Dic.16/dic.15 }\end{array}$ & $\begin{array}{c}\text { Var. } \\
\text { Dic.17/dic.16 }\end{array}$ \\
\hline Central Parking System Perú & 32,050 & 33,146 & 32,980 & $3.4 \%$ & $-0.5 \%$ \\
\hline Control Parking S.A.C & 9,410 & 9,881 & 9,800 & $5.0 \%$ & $-0.8 \%$ \\
\hline Los Portales S.A. & 91,694 & 91,827 & 90,786 & $0.1 \%$ & $-1.1 \%$ \\
\hline
\end{tabular}

Fuente: SMV $(2015,2016,2017)$

Elaboración propia

Podemos observar en el cuadro líneas abajo, que los Portales tiene la mayor participación entre sus principales competidores con más del $60 \%$ en el mercado nacional. 
Figura 8.18

Participación del sector estacionamiento

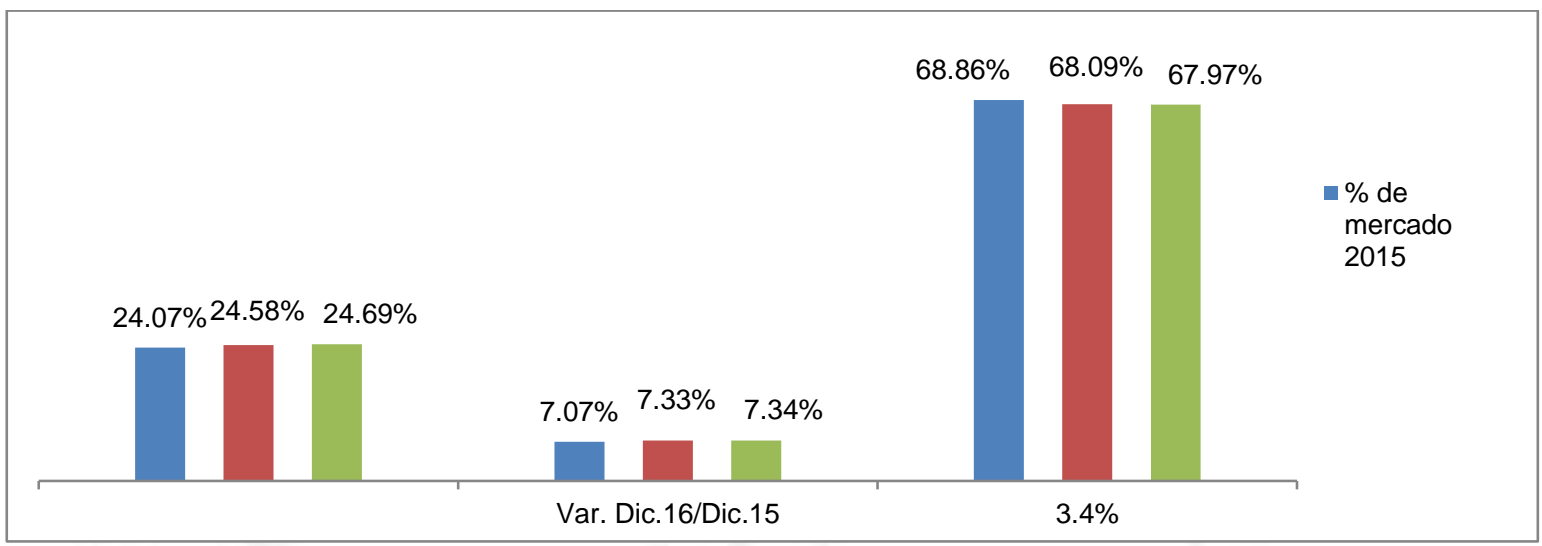

Fuente: SMV (2015, 2016, 2017)

Elaboración propia

Tabla 8.5

Rubro renta

\begin{tabular}{|l|c|c|c|c|c|}
\hline \multicolumn{1}{|c|}{ Empresa } & $\begin{array}{c}\text { Ventas } \\
\mathbf{2 0 1 5}\end{array}$ & $\begin{array}{c}\text { Ventas } \\
\mathbf{2 0 1 6}\end{array}$ & $\begin{array}{c}\text { Ventas } \\
\mathbf{2 0 1 7}\end{array}$ & $\begin{array}{c}\text { Var. } \\
\text { Dic.16/Dic.15 }\end{array}$ & $\begin{array}{c}\text { Var. } \\
\text { Dic.17/Dic.16 }\end{array}$ \\
\hline Los Portales S.A. & 2,211 & 2,217 & 2,174 & $0.27 \%$ & $-1.94 \%$ \\
\hline Inversiones Centenario S.A.A. & 53,342 & 60,311 & 56,246 & $13.06 \%$ & $-6.74 \%$ \\
\hline
\end{tabular}

Fuente: SMV $(2015,2016,2017)$

Elaboración propia

En el rubro de rentas (centros comerciales y oficinas), la que tiene mayor participación es la empresa Inversiones Centenario S.A.A., esto es gracias a que la mayor parte de centros comerciales de San Isidro y Surco son arrendados, como es el caso del centro Comercial Camino Real, Cronos, etc.

Figura 8.19

Participación del sector renta

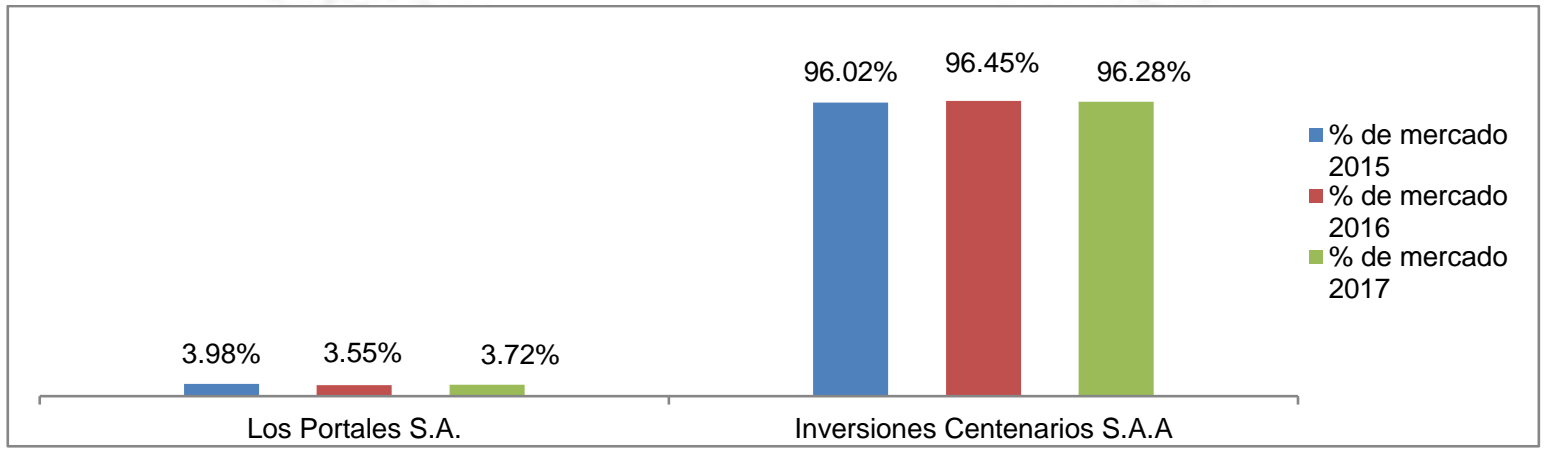

Fuente: SMV (2015, 2016, 2017)

Elaboración propia 


\section{Análisis de normas contables y cuentas contables y su impacto en los estados financieros}

Con respecto, a los impactos de las nuevas normas internacionales que entrarían en vigencia entre 2018 y 2019 se desarrollarán a continuación.

La compañía viene aplicando lo establecido por la NIC 39, para la medición posterior de las cuentas por cobrar. Sin embargo, con la futura aplicación de la NIIF 9 instrumentos financieros, se incorpora el modelo de pérdidas esperadas: "Las pérdidas crediticias esperadas son una estimación de la probabilidad ponderada de las pérdidas crediticias (es decir, el valor presente de las todas las insuficiencias de efectivo) a lo largo de la vida esperada del instrumento financiero.

Con esta nueva norma la empresa deberá reconocer los deterioros de forma anticipada, lo cual difiere con el modelo de pérdida incurrida, es decir todos los activos tendrán una pérdida por deterioro desde su reconocimiento inicial.

Basándonos en el hecho de la venta de lotes y departamentos se cobran en su totalidad en periodos largos, es decir, se cobran de manera fraccionada.

Es importante indicar que, al realizar la provisión de cobranza dudosa, se estaría realizando la pérdida esperada a lo largo de la vida del crédito. El impacto afectaría directamente a los resultados del ejercicio de Los Portales S.A. en el periodo en el cual se implemente esta norma y al ser un cambio en una estimación contable se reconocerá de forma prospectiva.

Por otro lado, la NIIF 15 - Ingresos de actividades ordinarias procedentes de contratos con clientes, que estaría reemplazando a la NIC 18 - Ingresos ordinarios y NIC 1- Presentación de estados financieros, de acuerdo a lo indicado por la gerencia, el segmento o rubro que impactaría significativamente, sería la venta de inmuebles, es por ello que la gerencia identificó que la parte de identificación del contrato del cliente es importante, ya que a pesar que evalúan los créditos de cada cliente, no es tan seguro para los segmentos D y E. Otro paso que impactaría es la identificación de obligaciones de desempeño en el contrato.

“La gerencia determinó que existe más de una obligación de desempeño separada a la transacción de venta de lotes urbanos i) Servicio de suministro de agua gratuita hasta que Sedapal instale la matriz de agua en los lotes 
urbanizados, y ii) La entrega de las áreas comunes de los proyectos inmobiliarios para uso de vivienda vacacional”. (SMV, 2018, P.44).

Con el cambio normativo, se considera que no se producirá una reducción en los ingresos en cada ejercicio y por ende no impactaría en los resultados de la empresa. Si bien es cierto hay diferencias a la hora de reconocer los ingresos, estas diferencias no son significativas entre la aplicación o no de NIC/NIIF, y en los indicadores financieros de la empresa Los Portales S.A., esas diferencias no serían sustanciales por aplicar las NIIF.

Por último, la NIIF 16, ¿Afectaría o impactaría la partida de pasivos?, esto debido a que se eliminaría los arrendamientos operativos y se empezaría a contabilizar como si fuera arrendamiento financiero.

Con el cambio normativo, la empresa deberá registrar periódicamente el gasto por depreciación dividiendo el valor presente de las cuotas de alquiler entre los meses del contrato de arrendamiento. Asimismo, el hecho de registrar periódicamente la cuota de alquiler pagada afectaría el gasto por intereses y a su vez la reducción del pasivo. Esta nueva normativa impactaría sobre los resultados de la empresa y su composición de pasivos.

A continuación, se realizará un caso práctico para evaluar el efecto en los estados financieros de la compañía:

Por ejemplo, si la empresa tiene un importe arrendado de S/ 120,000.00, con una tasa de interés del $8 \%$ por 5 años, ¿Qué efectos podría tener con la nueva norma en relación a la antigua?

\section{Ejemplo práctico:}

Tabla 8.6

Valor presente NIC 17

\begin{tabular}{ccc} 
& \multicolumn{1}{c}{ Pago } \\
\hline Año & 1 & $120,000.00$ \\
Año & 2 & $120,000.00$ \\
Año & 3 & $120,000.00$ \\
Año & 4 & $120,000.00$ \\
Año & 5 & $120,000.00$ \\
& & $\mathbf{6 0 0 , 0 0 0 . 0 0}$ \\
\hline
\end{tabular}

Fuente: Instituto Dogma

Elaboración propia 
Tabla 8.7

Tratamiento contable con NIC 17

\begin{tabular}{lcc}
\multicolumn{1}{c}{ Concepto } & Debe & Haber \\
Gasto por alquiler & $120,000.00$ & \\
$\begin{array}{l}\text { Pasivo por pagar } \\
\text { Reconocimiento inicial }\end{array}$ & & $120,000.00$ \\
\multicolumn{1}{c}{ Concepto } & Hebe & Haber \\
Pasivo por pagar & $120,000.00$ & \\
$\begin{array}{l}\text { Efectivo } \\
\text { Reconocimiento inicial }\end{array}$ & & $120,000.00$ \\
$\begin{array}{l}\text { Fuente: Instituto Dogma } \\
\text { Elaboración propia }\end{array}$ & &
\end{tabular}

Tabla 8.8

Valor presente NIIF 16

\begin{tabular}{|c|c|c|c|}
\hline & & Pago & $\begin{array}{c}\text { Valor } \\
\text { Presente }\end{array}$ \\
\hline Año & 1 & $120,000.00$ & $111,111.11$ \\
\hline Año & 2 & $120,000.00$ & $102,880.66$ \\
\hline Año & 3 & $120,000.00$ & $95,259.87$ \\
\hline Año & 4 & $120,000.00$ & $88,203.58$ \\
\hline \multirow[t]{2}{*}{ Año } & 5 & $120,000.00$ & $81,669.98$ \\
\hline & & $600,000.00$ & $479,125.20$ \\
\hline
\end{tabular}

Fuente: Instituto Dogma

Elaboración propia 
Tabla 8.9

Tratamiento contable con NIIF 16

\begin{tabular}{|c|c|c|}
\hline Concepto & Debe & Haber \\
\hline $\begin{array}{l}\text { Activo por contrato de arrendamiento } \\
\text { Pasivo por arrendamiento } \\
\text { Reconocimiento inicial }\end{array}$ & $479,125.20$ & $479,125.20$ \\
\hline Concepto & Debe & Haber \\
\hline $\begin{array}{l}\text { Pasivo por arrendamiento } \\
\text { Gasto financiero } \\
\text { Efectivo } \\
\text { Pago de 1ra cuota del arrendamiento }\end{array}$ & $\begin{array}{l}81,669.98 \\
38,330.02\end{array}$ & $120,000.00$ \\
\hline Concepto & Debe & Haber \\
\hline $\begin{array}{l}\text { Gasto por amortización } \\
\text { Activo por contrato de arrendamiento }\end{array}$ & $95,825.04$ & $95,825.04$ \\
\hline $\begin{array}{l}\text { Reconocimiento inicial } \\
\text { Fuente: Instituto Dogma } \\
\text { Elaboración propia }\end{array}$ & & \\
\hline
\end{tabular}

Ventas: Si en los próximos años aún siguieran con un entorno complejo reflejado por la caída de la demanda de viviendas, "ruido político", y no se prevé el Fenómeno del Niño Costero, impactaría fuertemente en los Estados de Resultados Proyectados en la cuenta de ingresos. No olvidemos que, en el 2017 debido a todas estas consecuencias, las ventas no crecieron como lo esperaba la gerencia, es más, el segmento más importante de la empresa Los Portales S.A. que es la venta inmobiliaria que disminuyó en un $7.92 \%$ con respecto al año anterior.

Inventarios: Con respecto, a lo señalado al entorno complejo en los próximos años, ésta cuenta también se vería afectado significativamente, ya que, al haber una caída de demanda de viviendas, habría stock de inventarios que no saldría a la venta, aumentando significativamente la cuenta de inmuebles terminados e inmuebles en desarrollo y terrenos en reserva. 
Efectivo y equivalencia de efectivo: La partida de efectivo y equivalencia de efectivo ayudó principalmente a pagar los préstamos bancarios y por ende hubo una disminución de los gastos financieros, sin embargo, una caída de la demanda de viviendas, la ley expuesta por el cobro por minuto en los estacionamientos impactaría en la partida y por ende el pago en las obligaciones financieras del corto plazo.

Otros pasivos financieros: Esta partida cada vez está creciendo principalmente por los bonos corporativos y papeles comerciales, es más han emitido por segunda vez el programa de bonos, por el cual se esperaría que ésta partida siga creciendo anualmente.

Costo de venta: En esta partida no se reflejaría que impactaría en los próximos años, gracias a su buena política de estructura de costos constante que se ha visto en los años anteriores.

Gastos financieros: Los gastos financieros podrían crecer anualmente, si es que aún continuaría con el entorno complejo interno, ya que en años anteriores la cuenta de efectivo y equivalencia de efectivo se ha estado usando para disminuir los préstamos bancarios y por ende los gastos financieros.

Propiedad de inversión: Esta cuenta podría impactar en los próximos años en el Estado de Situación Financiera, ya que, al ver una caída de demanda de vivienda, existiría un incremento de terrenos en reserva que no tenga aún fecha de desarrollo en el corto plazo.

\section{Proyecciones}

Por otro lado, para obtener las proyecciones del 2018 al 2020, se va necesitar datos como el PBI (rentas y estacionamientos), ¿Cuántos visitantes extranjeros y nacionales recibe el Perú? (hotel), así como las expectativas que tiene la institución CAPECO, que ve el crecimiento del rubro inmobiliario en los próximos años para la empresa Los Portales S.A.

De acuerdo al segmento del rubro inmobiliario, "el presidente de la Cámara Peruana de la Construcción estimó que el crecimiento del sector no sería igual al proyectado hacia inicios de año. En entrevista con Gestión.pe asegura que el crecimiento no bajará del 6\% hacia fines del 2018.” (Alarcón, 2018, párr. 1).

En las encuestas originadas por CAPECO nos indica que el crecimiento para el año 2018 según encuestas de empresas del sector construcción (inmobiliario, proveedores e infraestructura) será $6.19 \%$. 
Figura 8.20

Encuestas del sector construcción del año 2018

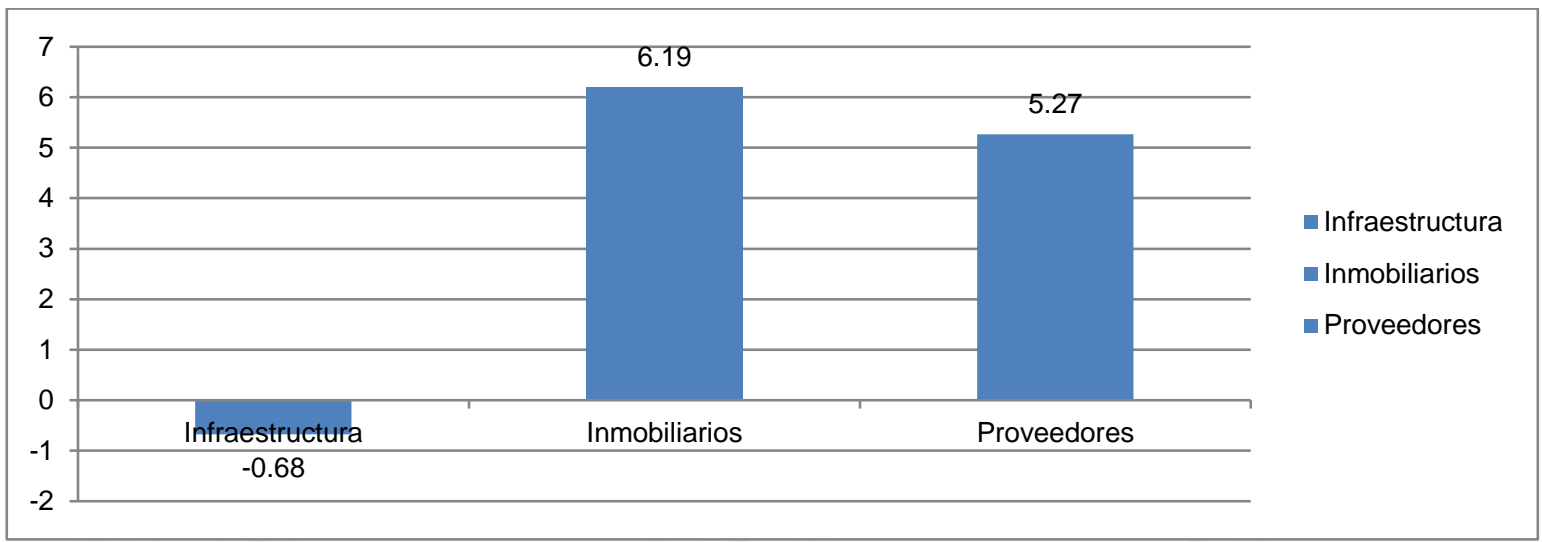

Fuente: CAPECO (2018)

Elaboración propia

Asimismo, en el rubro hotelería vemos que cada año se incrementan las personas que vienen al país y que se hospedan tanto nacionales e internacionales.

Tabla 8.10

Visitantes nacionales e internacionales (acumulado)

\begin{tabular}{|c|c|c|c|c|c|c|c|}
\hline & 2011 & 2012 & 2013 & 2014 & 2015 & 2016 & 2017 \\
\hline Arribo de Visitante (Millones) & 40.3 & 42.3 & 46.6 & 46.4 & 47.9 & 50.6 & 51.6 \\
\hline Variación \% & $28.34 \%$ & $4.96 \%$ & $10.17 \%$ & $0.43 \%$ & $3.23 \%$ & $5.64 \%$ & $1.98 \%$ \\
\hline
\end{tabular}

Fuente: Ministerio de Comercio Exterior y Turismo, [MINCENTUR], (2018)

Elaboración propia 
Tabla 8.11

PBI proyectado

Producto Bruto Interno por sectores

\begin{tabular}{|l|c|c|c|c|c|c|c|}
\hline & $\begin{array}{c}\text { Peso año } \\
\text { Base 2007 }\end{array}$ & 2017 & 2018 & 2019 & 2020 & 2021 & $\begin{array}{c}\text { Promedio } \\
2018-2021\end{array}$ \\
\hline Agropecuario & 6 & 2.6 & 4 & 4.2 & 4.2 & 4 & 4.1 \\
\hline Agrícola & 3.8 & 2.6 & 4.4 & 4.3 & 3.9 & 3.9 & 4.1 \\
\hline Pecuario & 2.2 & 2.7 & 3.3 & 4.2 & 4.2 & 4.2 & 4.0 \\
\hline Pesca & 0.7 & 4.7 & 24.8 & 4 & 4.2 & 4.4 & 9.4 \\
\hline Minería e hidrocarburos & 14.4 & 3.2 & 2.2 & 1.9 & 1.8 & 2.6 & 2.1 \\
\hline Manufactura & 16.5 & -0.3 & 3.7 & 3.6 & 4 & 4.3 & 3.9 \\
\hline Electricidad y agua & 1.7 & 1.1 & 3 & 3.5 & 4.5 & 4.5 & 3.9 \\
\hline Construcción & 5.1 & 2.2 & 9 & 7.8 & 7.8 & 7.8 & 8.1 \\
\hline Comercio & 10.2 & 1 & 2.6 & 4 & 4.2 & 4.5 & 3.8 \\
\hline Servicios & 37.1 & 3.4 & 3.8 & 4.8 & 5.2 & 5.5 & 4.8 \\
\hline PBI & 100 & 2.5 & 3.6 & 4.3 & 4.5 & 5 & 4.4 \\
\hline PBI primario & 25.2 & 2.9 & 3.7 & 2.7 & 2.6 & 3.1 & 3.0 \\
\hline PBI no primario & 66.5 & 2.2 & 3.9 & 4.8 & 5.1 & 5.4 & 4.8 \\
\hline
\end{tabular}

Fuente: Banco Central de Reserva del Perú, [BCRP], (2018)

Elaboración propia

\section{Política de proyecciones para los estados financieros}

En base a las proyecciones de los estados financieros 2018 - 2020, nos basaremos en proyecciones del PBI del sector construcción para segmento inmobiliario y el incremento de turistas alojados en el Perú.

\section{Principales políticas como base para la proyección de los estados financieros.}

Ingresos: Se toma el \% promedio de las proyecciones del PBI del sector construcción (MEF), para el caso hay una tasa promedio del 9\% de crecimiento para el 2018 y $7.8 \%$ para los años 2019 y 2020, todo esto en base a las proyecciones del MEF con respecto al PBI del sector inmobiliario.

Costo de ventas: Se toma el porcentaje de las ventas en los últimos 4 años, que para el caso de los Portales S.A. fue del 77\%, el cual se respetó para los años proyectados.

Gastos de ventas: Se toma el porcentaje de crecimiento de las ventas, que para el caso el gasto de ventas tiene un crecimiento en relación directa con el crecimiento de las ventas, es decir el 9\% para el año 2018 y $7.8 \%$ para los años 2019 y 2020. 
Gasto de administración: Es un gasto fijo, por lo que será el mismo gasto para todos los años proyectados.

Efectivo y equivalencia de efectivo: La proyección de efectivo dependerá del resultado del flujo de caja proyectado.

Cuentas por cobrar: Para las cuentas por cobrar se toma el \% promedio histórico de deudores con respecto a las ventas que para el caso es de $11.77 \%$ (porcentaje de ventas no cobradas) que se tomó como base de los años anteriores.

Inventario: Se establece como porcentaje del costo de ventas, que para el caso es del $101.3 \%$ del costo de ventas.

Propiedad, planta y equipo: Tomamos el crecimiento de esta cuenta en un $10 \%$, que son datos de los cálculos ya hechos a criterio de la dirección financiera.

Obligaciones financieras: Saldo de la deuda actual más las deudas nuevas.

Cuentas por pagar: Se toma el \% promedio histórico de las cuentas por pagar con respecto a las compras, que para el caso fue de $66 \%$ (porcentaje de lo que no se paga en el año).

Capital: Se mantiene constante a través de los años de proyección.

Resultados acumulados: se refiere al saldo de utilidades de los ejercicios anteriores más el resultado neto del Estado de Resultados Proyectado. 
Tabla 8.12

Proyección para los estados financieros 2018 - 2020

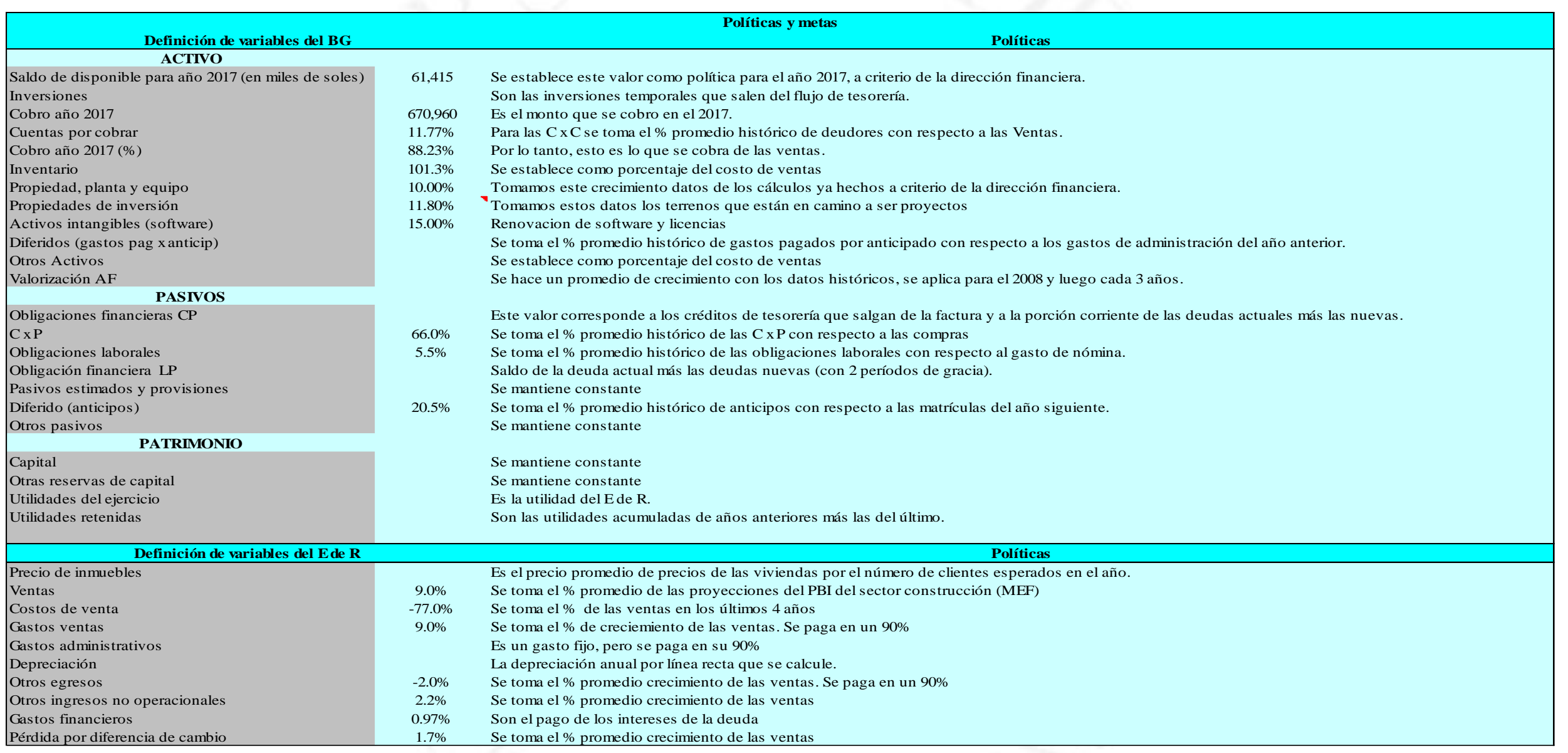

Fuente SMV (2018)

Elaboración propia 


\section{CAPÍTULO V: CONCLUSIONES}

1. La empresa Los Portales S.A. tiene como principal generador de ingresos el segmento de venta inmobiliaria, cuya participación es de más del 80\% impactando en los estados financieros de los años 2017, 2016 y 2015.

2. La empresa ha logrado mantener estable la estructura de costos y gastos. El gasto que muestran mayor cambio es la publicidad, que influye directamente en la venta de los inventarios.

3. El segmento de venta de inmuebles de la empresa Los Portales S.A. registra la mayor participación en el mercado nacional, seguida por el rubro de estacionamiento.

4. En relación a las partidas contables, la cuenta más significativa del activo son los inventarios que consideran los proyectos inmobiliarios en desarrollo e inmuebles terminados y en el caso de los pasivos destaca la cuenta de otros pasivos financieros que considera principalmente a los bonos corporativos, papeles comerciales, préstamos bancarios y préstamos con terceros.

5. Las principales empresas del sector inmobiliario, registran ratios financieros que muestran altos niveles de liquidez y mejoras en la gestión de ventas. Entre las empresas del sector Los Portales S.A. se presenta al 2017 con la mayor deuda y menor grado de propiedad.

6. A través de un adecuado manejo de los inventarios y cuentas por pagar, Los Portales S.A. ha logrado reducir su ciclo de conversión en efectivo al $12 \%$ aproximadamente con respecto al año anterior 2016, ello también tiene su efecto en los favorables índices de liquidez.

7. El alto nivel de apalancamiento, habría contribuido a las altas tasas de rentabilidad para los accionistas. Sin embargo, los socios no se han distribuido las utilidades, lo que permite identificar su compromiso con la empresa al reinvertir dichas ganancias. Esta decisión ha permitido que la compañía pueda responder ante cualquier situación desfavorable del mercado.

8. La empresa ha enfocado su crecimiento en el lanzamiento de nuevos proyectos lejos del bullicio de Lima y el continuo crecimiento de las necesidades de vivienda, es decir, potenciarlos y convertirlos en los primeros en el mercado. 
9. De acuerdo a las encuestas realizadas por CAPECO a las empresas del sector inmobiliario, infraestructura y proveedores del sector construcción, el año 2018 finalizará con un crecimiento promedio de $6 \%$ en las empresas de este rubro, mientras la utilidad neta proyectada del Estado de resultados, tendrá un incremento del 4\% constante en los próximos años desde el 2018 al 2020, tomando como referencia el 2017.

10. Los resultados de la investigación muestran que no existe diferencias significativas al aplicar la NIC/NIIF 15, ya que el tratamiento de la nueva norma no dista en demasía de la norma actual.

11. Los Portales S.A. evaluará el impacto en los estados financieros de las NIIF que entrarán en vigencia en los años 2018 y 2019. La gerencia ha informado que la NIIF 16 tendrá efecto en el pasivo y en el gasto financiero, dado que la empresa mantiene contratos de arrendamiento operativo que se registrarán como arrendamiento financiero. Asimismo, la NIIF 9 que se refiere a los riesgos de cobranza, impactaría significativamente en los resultados operativos de la de la compañía. 


\section{RECOMENDACIONES}

1. La empresa debe mantener la política de administración de costos y gastos, considerando que en los últimos 5 años esta estrategia le ha generado buenos resultados.

2. Considerando la estructura financiera actual de la empresa y su exposición en moneda extranjera generado por los pasivos de largo plazo, se recomienda evaluar el uso de coberturas financieras que limiten el impacto que un cambio en el tipo de cambio podría generarles a los resultados de la empresa.

3. Se debe analizar estrategias que permitan mejorar la gestión con proveedores para acceder a mayores montos y plazos, así apoyar el crecimiento del negocio, lo cual generaría un ahorro financiero.

4. Debe continuar con la política de reducción de los gastos financieros, optimizando la estructura de capital.

5. Continuar con la política de emisión de deuda en el mercado de capitales, lo cual ha significado en una estrategia de financiamiento más eficiente.

6. Para un mejor rendimiento de los activos, se recomienda a la empresa que verifique y evalúe correctamente sus propiedades, planta y equipo, ya que pudiera haber terrenos y propiedades que no estén generando beneficios. Debe procurarse solo mantener activos de carácter operativos.

7. Los Portales S.A. debe evaluar periódicamente el impacto que generaría la NIIF 9, monitoreando el efecto sobre los resultados de la empresa con el objetivo de mitigar su impacto.

8. La empresa debe analizar los impactos tributarios que podrían presentarse al entrar en rigor las nuevas normas internacionales en 2018 y 2019. 


\section{REFERENCIAS}

Ferrer, Quea, A. (2012). Estados financieros: Análisis e interpretación por sectores económicos. Lima: Instituto Pacífico.

Análisis de empresas. (2005). Bilbao: Ediciones Deusto.

Córdoba, M. (2014). Análisis financiero. Recuperado de http://www.elibro.com

Superintendencia de Mercado de Valores (2017). Estados Financieros Separados 31 de diciembre de 2017 y 31 de diciembre de 2016: Los Portales S.A.

Recuperado de

http://www.smv.gob.pe/ConsultasP8/temp/LOS\%20PORTALES\%20Separados \%202017.pdf

Ministerio de Economía y Finanzas. (2018). Proyecciones Macroeconómicas: Producto Bruto Interno (Variación porcentual real anual). Recuperado de https://www.mef.gob.pe/es/proyecciones-macroeconomicas

Alarcón, G. (13 de agosto del 2018). CAPECO espera menor crecimiento del sector construcción al previsto. Gestión. Recuperado de https://gestion.pe/

Bedregal, G y Salazar. E. (10 de mayo de 2018). Informe de Clasificación: Los Portales S.A. Recuperado de http://www.equilibrium.com.pe/LosPortales.pdf

Los Portales. (2018). Memoria Anual 2017. Recuperado de

http://www.losportalescorporativo.com.pe/upload/images/inversionistas/291818141803 $\underline{1 . p d f}$

Ministerio de Comercio Exterior y Turismo. (2018) Sistema de información estadística de turismo: Arribo, pernoctaciones y oferta hotelera en establecimientos de hospedaje. Recuperado de

http://datosturismo.mincetur.gob.pe/appdatosTurismo/Content3.html 


\section{BIBLIOGRAFÍA}

Cárdenas Bustíos, J. (24 de agosto del 2009). Reportes financieros: Los Portales S.A., Recuperado de http://centrum.pucp.edu.pe/adjunto/upload/publicacion/archivo/losportales.pdf

Ribbeck Gómez, C. (2014). Análisis e interpretación de estados financieros: herramienta clave para la toma de decisiones en las empresas de la industria metalmecánica del distrito de ate vitarte, 2013(tesis para el optar para el título de contador público, Universidad De San Martin De Porres) Recuperado de

http://www.repositorioacademico.usmp.edu.pe/bitstream/usmp/1112/1/ribbeck_gcg.pdf

Superintendencia de Mercado de Valores (2017). Estados Financieros Separados 31 de diciembre de 2017 y 31 de diciembre de 2016: Los Portales S.A.

Recuperado de

http://www.smv.gob.pe/ConsultasP8/temp/LOS\%20PORTALES\%20Separados \%202017.pdf

Superintendencia de Mercado de Valores (2015).Estados Financieros Separados 31 de diciembre de 2016 y 31 de diciembre de 2015: Los Portales S.A. Recuperado de http://www.smv.gob.pe/ConsultasP8/temp/DOC-20170324-WA0001.pdf

BCP eleva su proyección de crecimiento del PBI a 4\% en 2018 y 3,7\% en 2019 (07 de agosto del 2018). El Comercio. Recuperado de

https://elcomercio.pe/

Superintendencia de Mercado de Valores (2017) Estados Financieros Separados al 31 de diciembre de 2017 y de 2016 junto con el dictamen de los auditores independientes. Inversiones Centenario S.A.A. Recuperado de http://www.smv.gob.pe/ConsultasP8/temp/LOS\%20PORTALES\%20Separados \%202017.pdf

Superintendencia de Mercado de Valores (2017). Estados Financieros Separados al 31 de diciembre de 2016 y de 2015 junto con el dictamen de los auditores independientes. Inversiones Centenario S.A.A. Recuperado de http://www.smv.gob.pe/ConsultasP8/temp/EEFF\%20Consolidados\%20Inversio nes\%20Centenario.pdf

Superintendencia de Mercado de Valores (2018). Estados Financieros Separados al 31 de diciembre de 2017 y de 2016. Ciudaris Consultores Inmobiliarios S.A. Recuperado de http://www.smv.gob.pe/ConsultasP8/temp/Informe\%20Ciudaris\%202017.pdf 
ANEXOS 


\section{ANEXO 1: Estado Separado de Resultados Los Portales S.A.}

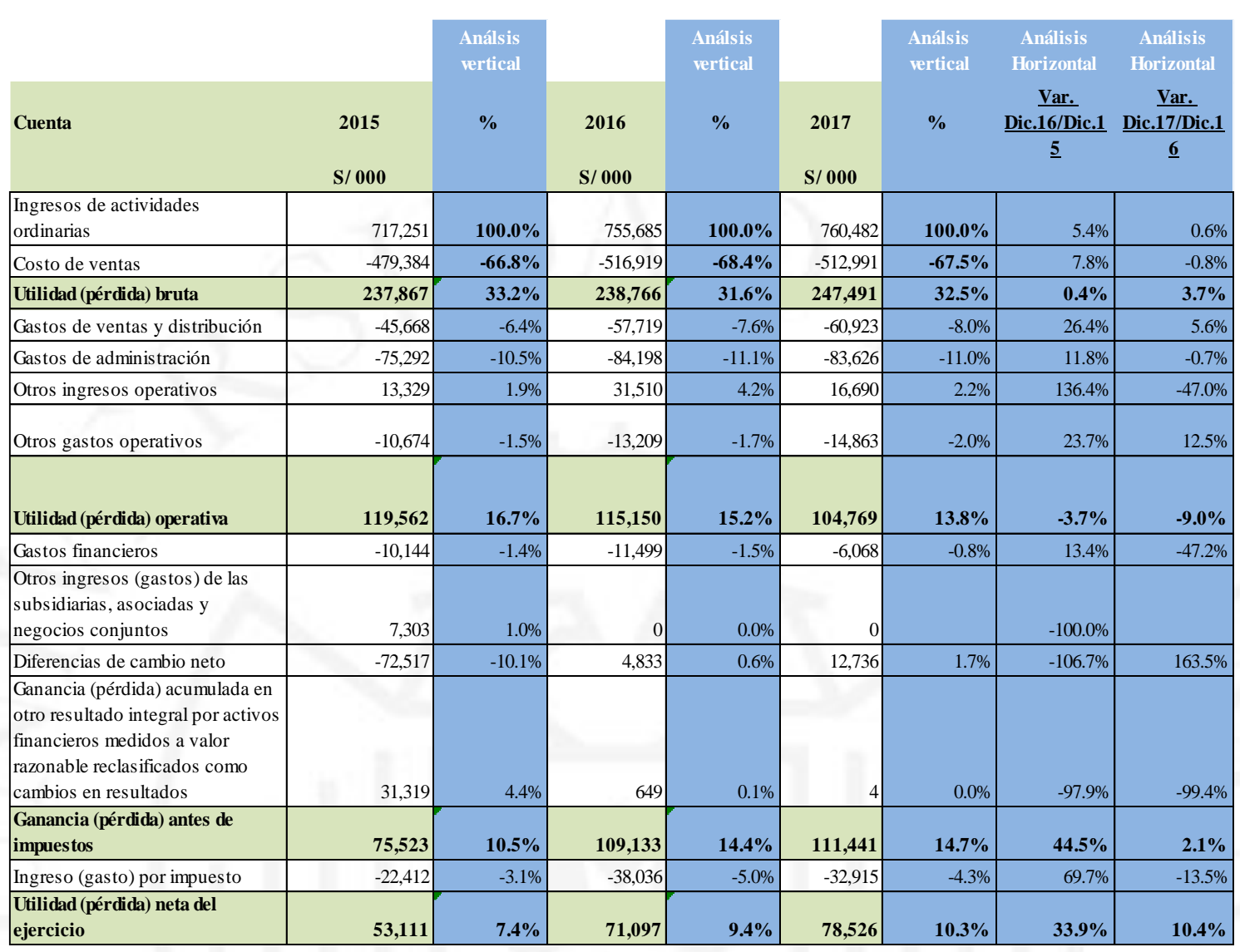

Fuente SMV $(2015,2016,2017)$

Elaboración propia 


\section{ANEXO 2: Estado Separado de Situación Financiera Los Portales S.A.}

\begin{tabular}{|c|c|c|c|c|c|c|c|c|}
\hline Cuenta & 2015 & $\%$ & 2016 & $\%$ & 2017 & $\%$ & $\begin{array}{c}\text { Var. } \\
\text { Dic.16/Dic. } \\
15\end{array}$ & $\begin{array}{c}\text { Var. } \\
\text { Dic.17/Dic. } \\
16\end{array}$ \\
\hline & $\mathrm{S} / 000$ & & $\mathrm{~S} / 000$ & & $\mathrm{~S} / 000$ & & & \\
\hline Efectivo y equivalentes de efectivo & 138,728 & $9.2 \%$ & 98,059 & $6.2 \%$ & 61,415 & $3.7 \%$ & $-29.3 \%$ & $-37.4 \%$ \\
\hline Cuentas por cobrar comerciales (neto) & 145,025 & $9.6 \%$ & 171,743 & $10.9 \%$ & 181,285 & $11.0 \%$ & $18.4 \%$ & $5.6 \%$ \\
\hline Otras cuentas por cobrar & 20,578 & $1.4 \%$ & 35,644 & $2.3 \%$ & 52,879 & $3.2 \%$ & $73.2 \%$ & $48.4 \%$ \\
\hline Inventarios & 494,254 & $32.6 \%$ & 475,090 & $30.1 \%$ & 519,459 & $31.6 \%$ & $-3.9 \%$ & $9.3 \%$ \\
\hline Otros activos no financieros & 2,720 & $0.2 \%$ & 1,628 & $0.1 \%$ & 1,835 & $0.1 \%$ & $-40.1 \%$ & $12.7 \%$ \\
\hline Total activo corriente & 801,305 & $52.9 \%$ & 782,164 & $49.5 \%$ & 816,873 & $49.7 \%$ & $-2.4 \%$ & $4.4 \%$ \\
\hline $\begin{array}{l}\text { Inversiones en subsidiarias, negocios } \\
\text { conjuntos y asociadas }\end{array}$ & 61,418 & $4.1 \%$ & 61,689 & $3.9 \%$ & 58,122 & $3.5 \%$ & $0.4 \%$ & $-5.8 \%$ \\
\hline Cuentas por cobrar comerciales & 269,656 & $17.8 \%$ & 320,378 & $20.3 \%$ & 400,358 & $24.4 \%$ & $18.8 \%$ & $25.0 \%$ \\
\hline Otras cuentas por cobrar & 3,000 & $0.2 \%$ & 3,000 & $0.2 \%$ & 0 & $0.0 \%$ & $0.0 \%$ & $-100.0 \%$ \\
\hline Propiedades de inversión & 189,372 & $12.5 \%$ & 217,686 & $13.8 \%$ & 178,908 & $10.9 \%$ & $15.0 \%$ & $-17.8 \%$ \\
\hline Propiedades, planta y equipo & 149,715 & $9.9 \%$ & 155,330 & $9.8 \%$ & 151,558 & $9.2 \%$ & $3.8 \%$ & $-2.4 \%$ \\
\hline $\begin{array}{l}\text { Activos intangibles distintos de la } \\
\text { plusvalía }\end{array}$ & 39,743 & $2.6 \%$ & 39,129 & $2.5 \%$ & 36,665 & $2.2 \%$ & $-1.5 \%$ & $-6.3 \%$ \\
\hline Total activo no corriente & 712,904 & $47.1 \%$ & 797,212 & $50.5 \%$ & 825,611 & $50.3 \%$ & $11.8 \%$ & $3.6 \%$ \\
\hline Total activo & $1,514,209$ & $100.0 \%$ & $1,579,376$ & $100.0 \%$ & $1,642,484$ & $100.0 \%$ & $4.3 \%$ & $4.0 \%$ \\
\hline Otros pasivos financieros & 195,335 & $12.9 \%$ & 164,188 & $10.4 \%$ & 154,644 & $9.4 \%$ & $-15.9 \%$ & $-5.8 \%$ \\
\hline Cuentas por pagar comerciales $\mathrm{CP}$ & 257,816 & $17.0 \%$ & 271,199 & $17.2 \%$ & 291,541 & $17.8 \%$ & $5.2 \%$ & $7.5 \%$ \\
\hline Otras cuentas por pagar & 125,378 & $8.3 \%$ & 117,811 & $7.5 \%$ & 119,686 & $7.3 \%$ & $-6.0 \%$ & $1.6 \%$ \\
\hline Otras provisiones & 2,475 & $0.2 \%$ & 1,862 & $0.1 \%$ & 1,699 & $0.1 \%$ & $-24.8 \%$ & $-8.8 \%$ \\
\hline Total pasivo corriente & 581,004 & $38.4 \%$ & 555,060 & $35.1 \%$ & 567,570 & $34.6 \%$ & $-4.5 \%$ & $2.3 \%$ \\
\hline Otros pasivos financieros & 475,809 & $31.4 \%$ & 475,949 & $30.1 \%$ & 467,929 & $28.5 \%$ & $0.0 \%$ & $-1.7 \%$ \\
\hline Cuentas por pagar comerciales LP & 57,205 & $3.8 \%$ & 79,583 & $5.0 \%$ & 76,485 & $4.7 \%$ & $39.1 \%$ & $-3.9 \%$ \\
\hline Pasivos por impuestos diferidos & 29,792 & $2.0 \%$ & 41,296 & $2.6 \%$ & 40,986 & $2.5 \%$ & $38.6 \%$ & $-0.8 \%$ \\
\hline Total pasivo no corriente & 562,806 & $37.2 \%$ & $\mathbf{5 9 6 , 8 2 8}$ & $37.8 \%$ & $\mathbf{5 8 5 , 4 0 0}$ & $35.6 \%$ & $6.0 \%$ & $-1.9 \%$ \\
\hline Total pasivo & $1,143,810$ & $75.5 \%$ & $1,151,888$ & $72.9 \%$ & $1,152,970$ & $70.2 \%$ & $0.7 \%$ & $0.1 \%$ \\
\hline Capital emitido & 171,254 & $11.3 \%$ & 171,254 & $10.8 \%$ & 171,254 & $10.4 \%$ & $0.0 \%$ & $0.0 \%$ \\
\hline Otras reservas de capital & 26,757 & $1.8 \%$ & 32,068 & $2.0 \%$ & 34,251 & $2.1 \%$ & $19.8 \%$ & $6.8 \%$ \\
\hline Resultados acumulados & 172,388 & $11.4 \%$ & 224,166 & $14.2 \%$ & 284,009 & $17.3 \%$ & $30.0 \%$ & $26.7 \%$ \\
\hline Total patrimonio neto & 370,399 & $24.5 \%$ & 427,488 & $27.1 \%$ & 489,514 & $29.8 \%$ & $15.4 \%$ & $14.5 \%$ \\
\hline Total pasivo y patrimonio neto & $1,514,209$ & $100.0 \%$ & $1,579,376$ & $100.0 \%$ & $1,642,484$ & $100.0 \%$ & $4.3 \%$ & $4.0 \%$ \\
\hline
\end{tabular}

Fuente SMV $(2015,2016,2017)$

Elaboración propia 


\section{ANEXO 3: Estado de Resultados por segmento Los Portales S.A. - venta inmobiliaria}

\begin{tabular}{|c|c|c|c|c|c|c|c|c|}
\hline & \multirow{2}{*}{\multicolumn{2}{|c|}{$\begin{array}{l}\text { Análsis } \\
\text { vertical }\end{array}$}} & \multirow{2}{*}{\multicolumn{2}{|c|}{$\begin{array}{l}\text { Análsis } \\
\text { vertical }\end{array}$}} & \\
\hline & & & & & & $\begin{array}{l}\text { Análsis } \\
\text { vertical }\end{array}$ & $\begin{array}{l}\text { Análisis } \\
\text { Horizontal }\end{array}$ & $\begin{array}{l}\text { Análisis } \\
\text { Horizontal }\end{array}$ \\
\hline Cuenta & $\begin{array}{l}2015 \\
\text { S/ } 000\end{array}$ & $\%$ & $\begin{array}{l}2016 \\
\text { S/ } 000\end{array}$ & $\%$ & $\begin{array}{l}2017 \\
\text { S/ } 000\end{array}$ & $\%$ & $\frac{\frac{\underline{\text { Var. }}}{\text { Dic.16/Dic.1 }}}{\underline{5}}$ & $\frac{\frac{\text { Var. }}{\text { Dic.17/Dic.1 }}}{\underline{6}}$ \\
\hline \begin{tabular}{|l|}
$\begin{array}{l}\text { Ingresos de actividades } \\
\text { ordinarias }\end{array}$ \\
\end{tabular} & 633,308 & $100.0 \%$ & 708,344 & $100.0 \%$ & 652,217 & $100.0 \%$ & $11.8 \%$ & $-7.9 \%$ \\
\hline Costo de ventas & $-421,709$ & $-66.6 \%$ & $-490,757$ & $-69.3 \%$ & $-432,599$ & $-66.3 \%$ & $16.4 \%$ & $-11.9 \%$ \\
\hline Utilidad (pérdida) bruta & 211,598 & $33.4 \%$ & 217,587 & $30.7 \%$ & 219,618 & $33.7 \%$ & $2.8 \%$ & $0.9 \%$ \\
\hline Gastos de ventas y distribución & $-37,621$ & $-5.9 \%$ & $-51,947$ & $-7.3 \%$ & $-54,831$ & $-8.4 \%$ & $38.1 \%$ & $5.6 \%$ \\
\hline Gastos de administración & $-62,026$ & $-9.8 \%$ & $-70,347$ & $-9.9 \%$ & $-68,925$ & $-10.6 \%$ & $13.4 \%$ & $-2.0 \%$ \\
\hline Otros ingresos operativos & 10,980 & $1.7 \%$ & 12,604 & $1.8 \%$ & 13,756 & $2.1 \%$ & $14.8 \%$ & $9.1 \%$ \\
\hline Otros gastos operativos & $-8,793$ & $-1.4 \%$ & $-11,036$ & $-1.6 \%$ & $-12,250$ & $-1.9 \%$ & $25.5 \%$ & $11.0 \%$ \\
\hline Utilidad (pérdida) operativa & 114,139 & $18.0 \%$ & 96,860 & $13.7 \%$ & 97,369 & $14.9 \%$ & $-15.1 \%$ & $0.5 \%$ \\
\hline Gastos financieros & $-8,357$ & $-1.3 \%$ & $-9,607$ & $-1.4 \%$ & $-5,001$ & $-0.8 \%$ & $15.0 \%$ & $-47.9 \%$ \\
\hline $\begin{array}{l}\text { Otros ingresos (gastos) de las } \\
\text { subsidiarias, asociadas y } \\
\text { negocios conjuntos }\end{array}$ & 6,016 & $0.9 \%$ & 0 & $0.0 \%$ & 0 & & $-100.0 \%$ & \\
\hline Diferencias de cambio neto & $-59,740$ & $-9.4 \%$ & 4,038 & $0.6 \%$ & 10,497 & $1.6 \%$ & $-106.8 \%$ & $160.0 \%$ \\
\hline $\begin{array}{l}\text { Ganancia (pérdida) acumulada en } \\
\text { otro resultado integral por activos } \\
\text { financieros medidos a valor } \\
\text { razonable reclasificados como } \\
\text { cambios en resultados }\end{array}$ & 25,801 & $4.1 \%$ & 542 & $0.1 \%$ & 3 & $0.0 \%$ & $-97.9 \%$ & $-99.4 \%$ \\
\hline \begin{tabular}{|l|} 
Ganancia (pérdida) antes de \\
impuestos
\end{tabular} & $\mathbf{7 7 , 8 5 9}$ & $12.3 \%$ & 91,833 & $13.0 \%$ & 102,868 & $15.8 \%$ & $17.9 \%$ & $12.0 \%$ \\
\hline Ingreso (gasto) por impuesto & $-23,105$ & $-3.6 \%$ & $-32,007$ & $-4.5 \%$ & $-30,383$ & $-4.7 \%$ & $38.5 \%$ & $-5.1 \%$ \\
\hline $\begin{array}{l}\text { Utilidad (pérdida) neta del } \\
\text { ejercicio }\end{array}$ & 54,754 & $8.6 \%$ & $\mathbf{5 9 , 8 2 7}$ & $8.4 \%$ & 72,485 & $11.1 \%$ & $9.3 \%$ & $21.2 \%$ \\
\hline
\end{tabular}

Fuente SMV $(2015,2016,2017)$

Elaboración propia 


\section{ANEXO 4: Estado de Situación Financiera por segmento Los Portales S.A. - venta inmobiliaria}

\begin{tabular}{|c|c|c|c|c|c|c|c|c|}
\hline & & \multirow[b]{2}{*}{$\begin{array}{l}\text { Análsis } \\
\text { vertical }\end{array}$} & & \\
\hline & & & & $\begin{array}{l}\text { Análsis } \\
\text { vertical }\end{array}$ & & $\begin{array}{l}\text { Análsis } \\
\text { vertical }\end{array}$ & $\begin{array}{c}\text { Análsis } \\
\text { horizontal }\end{array}$ & $\begin{array}{c}\text { Análsis } \\
\text { horizontal }\end{array}$ \\
\hline \multirow[t]{2}{*}{ Cuenta } & 2015 & $\%$ & 2016 & $\%$ & 2017 & $\%$ & $\begin{array}{c}\text { Var. } \\
\text { Dic.16/Dic. } \\
15\end{array}$ & $\begin{array}{c}\text { Var. } \\
\text { Dic.17/Dic. } \\
16\end{array}$ \\
\hline & $S / 000$ & & $\mathrm{~S} / 000$ & & $\mathrm{~S} / 000$ & & & \\
\hline Efectivo y equivalentes de efectivo & 122,492 & $9.2 \%$ & 91,916 & $6.2 \%$ & 52,672 & $3.7 \%$ & $-25.0 \%$ & $-42.7 \%$ \\
\hline Cuentas por cobrar comerciales (neto) & 128,052 & $9.6 \%$ & 160,984 & $10.9 \%$ & 155,477 & $11.0 \%$ & $25.7 \%$ & $-3.4 \%$ \\
\hline Otras cuentas por cobrar & 18,170 & $1.4 \%$ & 33,411 & $2.3 \%$ & 45,351 & $3.2 \%$ & $83.9 \%$ & $35.7 \%$ \\
\hline Inventarios & 436,409 & $32.6 \%$ & 445,327 & $30.1 \%$ & 445,507 & $31.6 \%$ & $2.0 \%$ & $0.0 \%$ \\
\hline Otros activos no financieros & 2,402 & $0.2 \%$ & 1,526 & $0.1 \%$ & 1,574 & $0.1 \%$ & $-36.5 \%$ & $3.1 \%$ \\
\hline Total activo corriente & 707,524 & $52.9 \%$ & 733,164 & $49.5 \%$ & 700,580 & $49.7 \%$ & $3.6 \%$ & $-4.4 \%$ \\
\hline $\begin{array}{l}\text { Inversiones en subsidiarias, negocios } \\
\text { conjuntos y asociadas }\end{array}$ & 54,230 & $4.1 \%$ & 57,824 & $3.9 \%$ & 49,848 & $3.5 \%$ & $6.6 \%$ & $-13.8 \%$ \\
\hline Cuentas por cobrar comerciales & 238,097 & $17.8 \%$ & 300,307 & $20.3 \%$ & 343,362 & $24.4 \%$ & $26.1 \%$ & $14.3 \%$ \\
\hline Otras cuentas por cobrar & 2,649 & $0.2 \%$ & 2,812 & $0.2 \%$ & 0 & $0.0 \%$ & $6.2 \%$ & $-100.0 \%$ \\
\hline Propiedades de inversión & 167,209 & $12.5 \%$ & 204,049 & $13.8 \%$ & 153,438 & $10.9 \%$ & $22.0 \%$ & $-24.8 \%$ \\
\hline Propiedades, planta y equipo & 132,193 & $9.9 \%$ & 145,599 & $9.8 \%$ & 129,982 & $9.2 \%$ & $10.1 \%$ & $-10.7 \%$ \\
\hline $\begin{array}{l}\text { Activos intangibles distintos de la } \\
\text { plusvalía }\end{array}$ & 35,092 & $2.6 \%$ & 36,678 & $2.5 \%$ & 31,445 & $2.2 \%$ & $4.5 \%$ & $-14.3 \%$ \\
\hline Total activo no corriente & 629,469 & $47.1 \%$ & 747,269 & $\mathbf{5 0 . 5 \%}$ & 708,074 & $50.3 \%$ & $18.7 \%$ & $-5.2 \%$ \\
\hline Total activo & $1,336,994$ & $100.0 \%$ & $1,480,434$ & $100.0 \%$ & $1,408,654$ & $100.0 \%$ & $10.7 \%$ & $-4.8 \%$ \\
\hline Otros pasivos financieros & 172,474 & $12.9 \%$ & 153,902 & $10.4 \%$ & 132,628 & $9.4 \%$ & $-10.8 \%$ & $-13.8 \%$ \\
\hline Cuentas por pagar comerciales $\mathrm{CP}$ & 227,643 & $17.0 \%$ & 254,209 & $17.2 \%$ & 250,036 & $17.8 \%$ & $11.7 \%$ & $-1.6 \%$ \\
\hline Otras cuentas por pagar & 110,704 & $8.3 \%$ & 110,431 & $7.5 \%$ & 102,647 & $7.3 \%$ & $-0.2 \%$ & $-7.0 \%$ \\
\hline Otras provisiones & 2,185 & $0.2 \%$ & 1,745 & $0.1 \%$ & 1,457 & $0.1 \%$ & $-20.1 \%$ & $-16.5 \%$ \\
\hline Total pasivo corriente & 513,006 & $38.4 \%$ & 520,287 & $35.1 \%$ & 486,769 & $34.6 \%$ & $1.4 \%$ & $-6.4 \%$ \\
\hline Otros pasivos financieros & 420,123 & $31.4 \%$ & 446,132 & $30.1 \%$ & 401,313 & $28.5 \%$ & $6.2 \%$ & $-10.0 \%$ \\
\hline Cuentas por pagar comerciales LP & 50,510 & $3.8 \%$ & 74,597 & $5.0 \%$ & 65,596 & $4.7 \%$ & $47.7 \%$ & $-12.1 \%$ \\
\hline Pasivos por impuestos diferidos & 26,305 & $2.0 \%$ & 38,709 & $2.6 \%$ & 35,151 & $2.5 \%$ & $47.2 \%$ & $-9.2 \%$ \\
\hline Total pasivo no corriente & 496,938 & $37.2 \%$ & 559,439 & $\mathbf{3 7 . 8 \%}$ & 502,060 & $35.6 \%$ & $12.6 \%$ & $-10.3 \%$ \\
\hline Total pasivo & $1,009,944$ & $75.5 \%$ & $1,079,726$ & $72.9 \%$ & 988,829 & $70.2 \%$ & $6.9 \%$ & $-8.4 \%$ \\
\hline Capital emitido & 151,211 & $11.3 \%$ & 160,526 & $10.8 \%$ & 146,874 & $10.4 \%$ & $6.2 \%$ & $-8.5 \%$ \\
\hline Otras reservas de capital & 23,625 & $1.8 \%$ & 30,059 & $2.0 \%$ & 29,375 & $2.1 \%$ & $27.2 \%$ & $-2.3 \%$ \\
\hline Resultados acumulados & 152,213 & $11.4 \%$ & 210,123 & $14.2 \%$ & 243,576 & $17.3 \%$ & $38.0 \%$ & $15.9 \%$ \\
\hline Total patrimonio neto & 327,049 & $24.5 \%$ & 400,707 & $27.1 \%$ & 419,825 & $29.8 \%$ & $22.5 \%$ & $4.8 \%$ \\
\hline Total pasivo y patrimonio neto & $1,336,994$ & $100.0 \%$ & $1,480,434$ & $100.0 \%$ & $1,408,654$ & $100.0 \%$ & $10.7 \%$ & $-4.8 \%$ \\
\hline
\end{tabular}

Fuente SMV $(2015,2016,2017)$

Elaboración propia 


\section{ANEXO 5: Estado de Resultado proyectado 2018-2020}

\begin{tabular}{|c|c|c|c|c|c|}
\hline & Año base & Año 2018 & Año 2019 & Año 2020 \\
\hline & & $S / 000$ & $S / 000$ & $S / 000$ & $S / 000$ \\
\hline \multirow[b]{5}{*}{$.77 \%$} & Ventas & $760,482.00$ & $823,547.08$ & $883,108.33$ & $946,323.06$ \\
\hline & Ingresos por venta de inmuebles & $538,641.00$ & $587,118.69$ & $632,913.95$ & $682,281.24$ \\
\hline & Ingresos por servicios prestados(hoteles, estacionamientos y rentas) & $136,525.00$ & $143,433.95$ & $149,946.38$ & $155,974.47$ \\
\hline & Ingresos por financiamiento de venta de inmueble & $85,316.00$ & $92,994.44$ & $100,248.01$ & $108,067.35$ \\
\hline & Costo de ventas & $-512,991.00$ & $-555,293.68$ & $-595,245.39$ & $-637,599.96$ \\
\hline \multirow[t]{5}{*}{$.72 \%$} & Costo de venta de inmuebles & $-414,842.00$ & $-452,177.78$ & $-487,447.65$ & $-525,468.56$ \\
\hline & Costos por servicios prestados(hoteles y estacionamiento) & $-98,149.00$ & $-103,115.90$ & $-107,797.75$ & $-112,131.39$ \\
\hline & Utilidad bruta & $247,491.00$ & $268,253.40$ & $287,862.94$ & $308,723.10$ \\
\hline & Cambio en el valor razonable de propiedades de inversion & 4.00 & & & \\
\hline & Gastos de ventas & $-60,923.00$ & $-66,406.07$ & $-71,585.74$ & $-77,169.43$ \\
\hline $2 \%$ & Gatos de administracion & $-83,626.00$ & $-83,626.00$ & $-83,626.00$ & $-83,626.00$ \\
\hline \multirow[t]{5}{*}{$.2 \%$} & Otros ingresos & $16,690.00$ & $18,074.06$ & $19,381.23$ & $20,768.58$ \\
\hline & Otros gastos & $-14,863.00$ & $-16,095.56$ & $-17,259.63$ & $-18,495.11$ \\
\hline & Utilidad operativa & $104,773.00$ & $120,199.84$ & $134,772.80$ & $150,201.14$ \\
\hline & Gastos financieros & $-6,068.00$ & $-6,127.14$ & $-6,186.29$ & $-6,245.43$ \\
\hline & Diferencia en cambio, neta & $12,736.00$ & $13,792.17$ & $14,789.66$ & $15,848.33$ \\
\hline \multirow[t]{4}{*}{$29.5 \%$} & Utilidad antes de impuestps & $111,441.00$ & $127,864.86$ & $143,376.17$ & $159,804.04$ \\
\hline & Impuesto a la renta & $-32,915.00$ & $-37,720.14$ & $-42,295.97$ & $-47,142.19$ \\
\hline & Utilidad neta & $78,526.00$ & $90,144.73$ & $101,080.20$ & $112,661.85$ \\
\hline & Compras & $557,360.00$ & $598,129.73$ & $635,700.83$ & $680,488.54$ \\
\hline
\end{tabular}

Fuente SMV (2017)

Elaboración propia 


\section{ANEXO 6: Estado de Situación Financiera proyectado 2018- 2020}

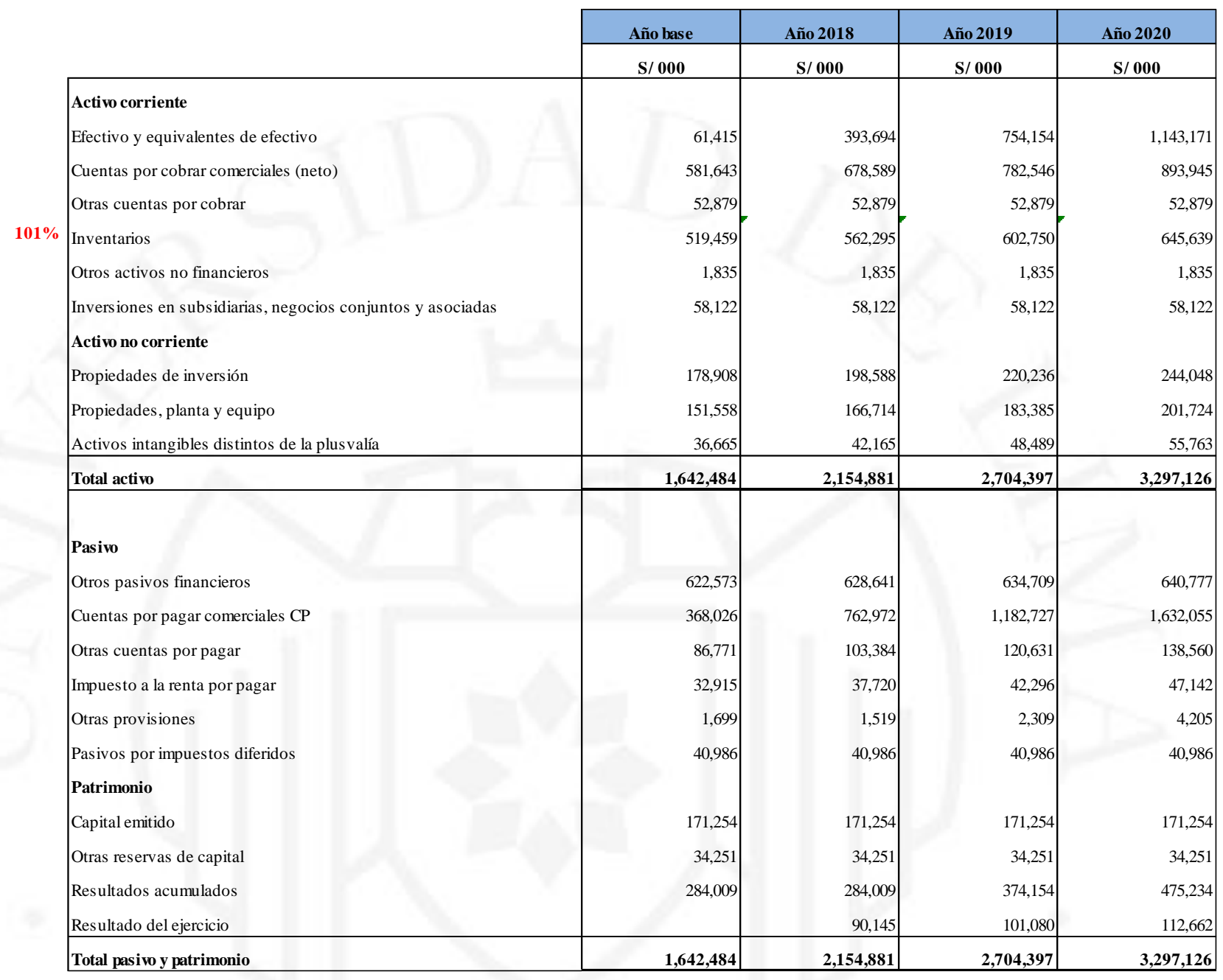

Fuente SMV (2017)

Elaboración propia 